\title{
Total Synthesis of Entecavir
}

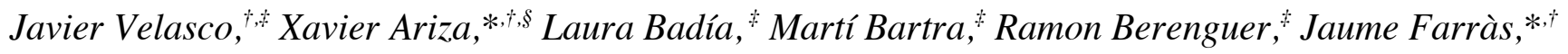
Joan Gallardo ${ }^{\dagger}$ Jordi Garcia ${ }^{\dagger, 8}$ and Yolanda Gasanz ${ }^{\star}$

'Departament de Química Orgànica and Institut de Biomedicina de la Universitat de Barcelona (IBUB), Facultat de Química, Universitat de Barcelona, Martí i Franquès 1,08028-Barcelona, Spain ${ }^{*}$ R\&D Department, Esteve Química S.A., Caracas 17-19, 08030-Barcelona, Spain

${ }^{\S}$ CIBER Fisiopatología de la Obesidad y la Nutrición (CIBERobn), Instituto de Salud Carlos III, Madrid, Spain

jfarras@ub.edu,xariza@ub.edu

RECEIVED DATE

TITLE RUNNING HEAD: Total Synthesis of Entecavir

CORRESPONDING AUTHOR FOOTNOTE: Corresponding author. Tel.: +34 934021248; fax: +34 933397878.

\begin{abstract}
:
Entecavir (BMS-200475) was synthesized from 4-trimethylsilyl-3-butyn-2-one and acrolein. The key features of its preparation are: (i) a stereoselective boron-aldol reaction to afford the acyclic carbon skeleton of the methylenecylopentane moiety; (ii) its cyclization by a $\mathrm{Cp}_{2} \mathrm{TiCl}$-catalyzed intramolecular radical addition of an epoxide to an alkyne; and (iii) the coupling with a purine derivative by a
\end{abstract}


Mitsunobu reaction.

KEYWORDS. Hepatitis B, antiviral, total synthesis, aldol reaction, radical cyclization, carbocyclic nucleoside

\section{Introduction}

B-type hepatitis is a global disease. It is one of the most common viral infections worldwide despite an efficient vaccine being available since 1982. According to the World Health Organization (WHO) about two billion people are infected worldwide and 600,000 die every year due to consequences such as cirrhosis of the liver or liver cancer. Hepatitis B can manifest itself in both acute and chronic forms and is especially dangerous in children. About $90 \%$ of infants infected during the first year of life develop chronic infections, although this ratio drops to $30-50 \%$ in children infected between the ages of one and four. About $25 \%$ of adults who become chronically infected during childhood will die from hepatitis Brelated liver cancer or cirrhosis while about $90 \%$ of people who become infected during adulthood will recover and be completely free of the virus within six months. About 240 million people are thought to be chronically infected with the disease worldwide. ${ }^{1}$

In its chronic form hepatitis B can be treated with interferon or antiviral agents. The most frequently used antiviral agents against hepatitis B virus (HBV) are entecavir (1), tenofovir, adefovir, telbivudine, and lamivudine (Figure 1). ${ }^{2}$ 


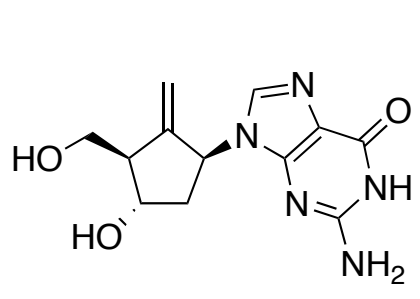

Entecavir (1)

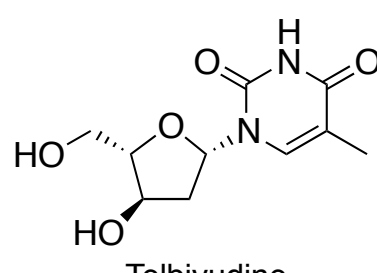

Telbivudine<smiles>[R][C@H](Cn1cnc2c(N)ncnc21)OCP(=O)(O)O</smiles>

Tenofovir $(\mathrm{R}=\mathrm{Me})$ Adefovir $(\mathrm{R}=\mathrm{H})$<smiles>Nc1ccn([C@H]2CS[C@@H](CO)O2)c(=O)n1</smiles>

Lamivudine

Figure 1. Antiviral agents used against HBV.

Of these, entecavir is considered one of the best choices for the treatment of chronic patients due to its lack of significant adverse effects and the low risk of inducing long-term resistance to the drug. ${ }^{3}$

Entecavir (BMS-200475), first synthesized by Bristol-Myers Squibb, ${ }^{4}$ was identified as a potent inhibitor of $\mathrm{HBV}$ in vitro $\left(\mathrm{ED}_{50}=3 \mathrm{nM}\right)^{5}$ and was later commercialized as Baraclude ${ }^{\circ}$. Its patent is due to expire in 2015 in the US and soon afterwards in other countries. In anticipation of the availability of a generic version, a plethora of patent applications has appeared recently ${ }^{6,8 a-b}$ Most the reported synthetic approaches for the stereoselective construction of the cyclopentane framework are based on transformation of a cyclopentane moiety, ${ }^{6,7}$ and only a few start with an acyclic precursor that is subsequently cyclized. ${ }^{8}$ In this paper we disclose a concise synthesis of $\mathbf{1}$ from acyclic precursors. ${ }^{9}$ As shown in Scheme 1, the retrosynthetic analysis of this carbocyclic nucleoside ${ }^{10}$ takes advantage of the ability of epoxides to act as effective precursors of radicals. The key step involves the Ti(III)-mediated generation of a $\beta$-alkoxy carbon radical ${ }^{11}$ from epoxide $\mathbf{4}$ that can cyclize to a methylene cyclopentane 5 through the cyclic transition state shown in Figure 2. 


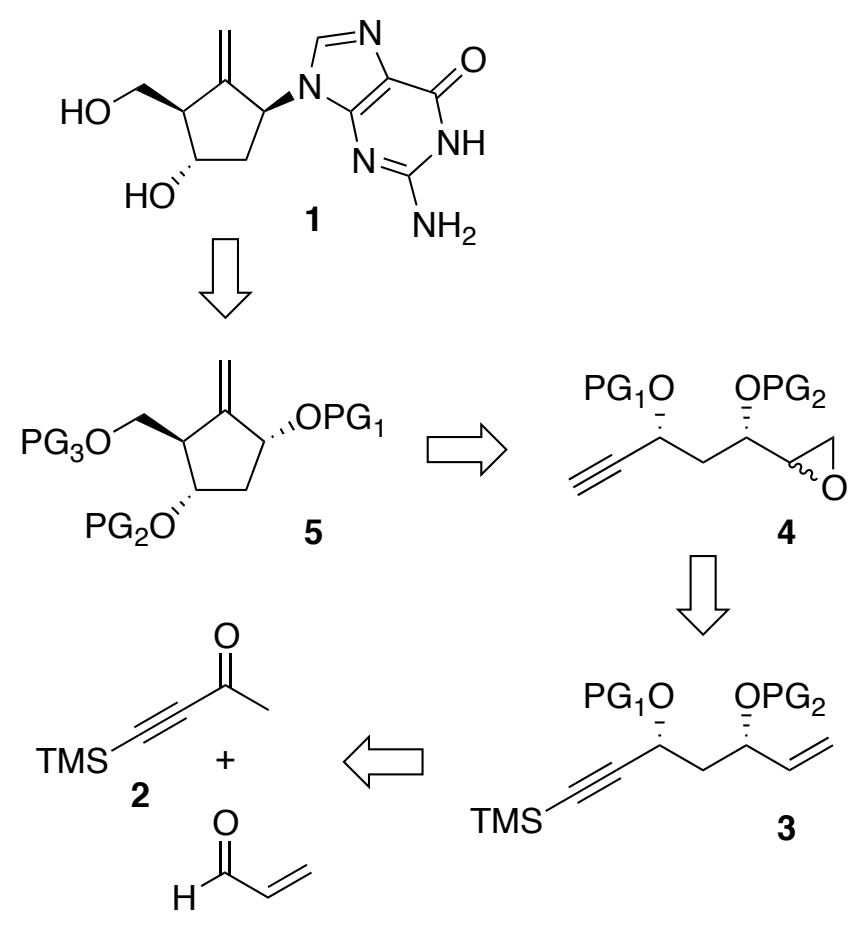

Scheme 1

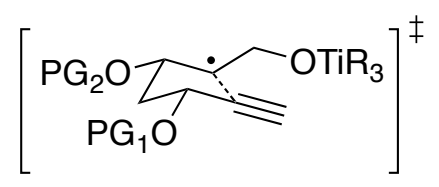

Figure 2. Proposed TS for the radicalary cyclization of 4.

It is worth noting that the proposed radical cyclization has been reported previously in a failed attempt to prepare 1. Thus, Ziegler ${ }^{12}$ prepared epoxide $\mathbf{4 b}\left(\mathrm{PG}_{1}=\mathrm{PG}_{2}=\mathrm{TBS}\right)$ from protected D-glucose in 9 steps and reported very good cyclization yields when $\mathbf{4 b}$ was treated with 3 equiv of $\mathrm{Cp}_{2} \mathrm{TiCl}_{2}$ in the presence of an excess of $\mathrm{Zn}$ in THF. Considering these precedents, we implemented an alternative route to epoxides 4 where the key step is an enantioselective acetate aldol addition ${ }^{13}$ of methyl ketone 2 to acrolein followed by the in situ reduction of the corresponding $\beta$-hydroxy ketone. This approach drastically reduces the number of steps involved and potentially provides more flexibility with respect to the election of protecting groups $\left(\mathrm{PG}_{1}\right.$ and $\left.\mathrm{PG}_{2}\right)$. 


\section{Results and Discussion}

The enantioselective aldol reaction of 4-trimethylsilyl-3-butyn-2-one (2) with acrolein was carried out using (+)-chlorodiisopinocampheylborane ((+)-DIPCl) as source of chirality. ${ }^{14}$ As shown in Scheme 2, the in situ reduction of the resulting chelate ${ }^{15}$ with $\mathrm{LiBH}_{4}$ followed by an oxidative work up provided 3a $\left(\mathrm{PG}_{1}=\mathrm{PG}_{2}=\mathrm{H}\right)$ as a mixture of diols in $66 \%$ yield and moderate selectivity (80:20 er, 90:10 syn/anti ratio) after chromatography. It is worth noting that recrystallization from hexanes afforded pure syn diol 3a ( $98 \%$ er, $>99 \%$ dr) in $37 \%$ overall yield. Despite the low yield, this method is very straightforward and allows the skeleton of the cyclization precursor 4 to be constructed from easily available commercial starting materials in a one-pot procedure.

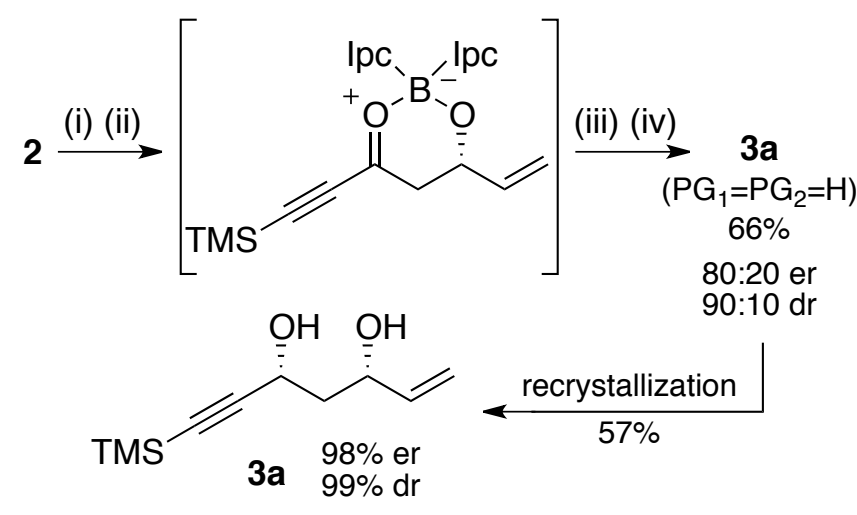

(i) (+)-DIPCl, $\mathrm{NEt}_{3}, \mathrm{THF},-5 \rightarrow 0{ }^{\circ} \mathrm{C}, 2 \mathrm{~h}$; (ii) acrolein, $-78^{\circ} \mathrm{C}$, $1 \mathrm{~h}$; (iii) $\mathrm{LiBH}_{4},-78^{\circ} \mathrm{C}, 1 \mathrm{~h}$; (iv) $\mathrm{H}_{2} \mathrm{O}_{2}, \mathrm{NaOAc}, \mathrm{THF}: \mathrm{H}_{2} \mathrm{O}$, rt, $0.5 \mathrm{~h}$.

\section{Scheme 2}

Conversion of 3a into the Ziegler's epoxide $\mathbf{4 b}$ or its TMS-derivative $\mathbf{6}$ is very efficient (Scheme 3). Unfortunately, the cyclization of $\mathbf{4 b}$ leads to the methylene cyclopentane $\mathbf{5 b}\left(\mathrm{PG}_{1}=\mathrm{PG}_{2}=\mathrm{TBS}, \mathrm{PG}_{3}=\mathrm{H}\right.$, Scheme 1) where the differentiation of TBS ethers would be problematic during the introduction of the nucleobase. On the other hand, our preliminary attempts at the cyclization of epoxide $\mathbf{6}$ led to the complete degradation of the starting material. With a view to circumventing these limitations we evaluated the cyclization reactions for a series of epoxides of type $\mathbf{4}$ with different protecting groups 
(Scheme $1, \mathrm{PG}_{1} \neq \mathrm{PG}_{2}$ ).

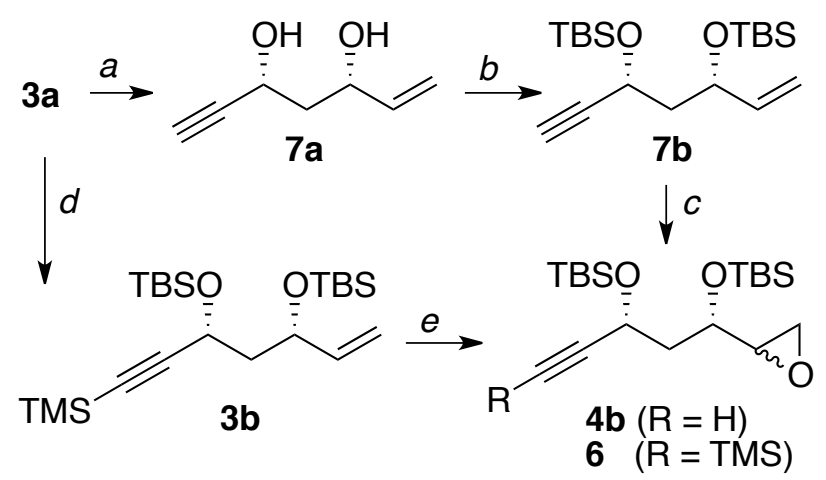

(a) $\mathrm{K}_{2} \mathrm{CO}_{3}, \mathrm{MeOH}, 1 \mathrm{~h}, \mathrm{rt}, 98 \%$; (b) TBSCl, imidazole, $\mathrm{CH}_{2} \mathrm{Cl}_{2}, 15 \mathrm{~h}$, rt, 95\%; (c) m-CPBA, $\mathrm{CH}_{2} \mathrm{Cl}_{2}, 15 \mathrm{~h}, \mathrm{rt}, \mathbf{4 b}$ : 95\%; (d) TBSCl, imidazole, $\mathrm{CH}_{2} \mathrm{Cl}_{2}$, rt, 96\%; (e) $m$-CPBA, $\mathrm{CH}_{2} \mathrm{Cl}_{2}, 15 \mathrm{~h}$, rt, 6: $91 \%$.

\section{Scheme 3}

Preparation of $4\left(\mathrm{PG}_{1} \neq \mathrm{PG}_{2}\right)$ from 3a or $\mathbf{7 a}$ is not trivial in some cases because there is no reliable information in the literature on the selective monoprotection of secondary propargylic alcohols in the presence of secondary allylic ones. In order to establish the viability of the monoprotection reactions, a set of silylations and benzoylations were carried out on these diols. Table 1 summarizes the optimized conditions found for each substrate and highlights the fact that protection of the propargylic position is clearly favored over the protection of the corresponding allylic position. Moderate-to-good yields of the desired monoprotected diol can be achieved while at the same time maintaining the yields of diprotected byproducts below $15 \%$. Yields of the monoprotected allylic alcohol are less than 5\%.

\section{TABLE 1. Monoprotection of diols $3 a$ and $7 \mathbf{a}$.}

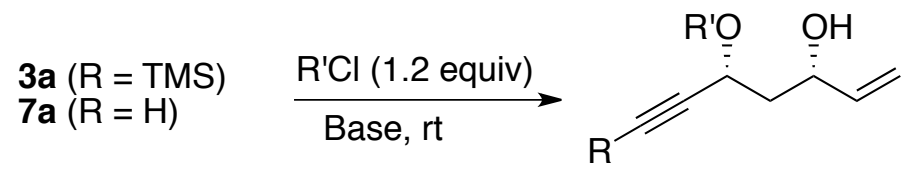

\begin{tabular}{|c|c|c|c|c|c|c|c|}
\hline Entry & Diol & $\mathrm{R}$ & $\mathrm{R}^{\prime}$ & Base & Solvent & $t(\mathrm{~h})$ & Yield (product) \\
\hline $1^{a}$ & $\mathbf{3 a}$ & TMS & TBS & Imidazole & THF & 5 & $65 \%(\mathbf{3 c})$ \\
\hline 2 & $\mathbf{3 a}$ & TMS & TBDPS & Imidazole & THF & 5 & $62 \%(3 d)$ \\
\hline
\end{tabular}




\begin{tabular}{|c|c|c|c|c|c|c|c|}
\hline 3 & $\mathbf{3 a}$ & TMS & TIPS & Imidazole & THF & 15 & $69 \%(\mathbf{3 e})$ \\
\hline $5^{a}$ & $\mathbf{7 a}$ & $\mathrm{H}$ & $\mathrm{TBS}$ & Imidazole & $\mathrm{CH}_{2} \mathrm{Cl}_{2}$ & 5 & $54 \%(\mathbf{7 c})$ \\
\hline $6^{a}$ & $\mathbf{7 a}$ & $\mathrm{H}$ & $\mathrm{Bz}$ & DIPEA & $\mathrm{CH}_{2} \mathrm{Cl}_{2}$ & 15 & $86 \%(\mathbf{7 f})$ \\
\hline
\end{tabular}

${ }^{a} \mathrm{R}$ 'Cl (1.1 equiv) was added.

Based on these results, we attempted to prepare the diprotected epoxides $\mathbf{4 g}$-j (Scheme 4) through selective monoprotection of 3a followed by the removal of the TMS group to afford 7c-e monoalcohols. The sequence was completed by epoxidation with $m$-CPBA and final protection of the remaining alcohol. The alternative pathway, in which the epoxidation was the final step was less convenient since the epoxidation of protected allylic alcohols is slow and it is even slower with acetylated allylic alcohols. On the other hand, for the preparation of $\mathbf{4 k}$ via $\mathbf{7 f}$ removal of the TMS group of $\mathbf{3 a}$ to afford diol 7a was the first step in the sequence since this deprotection was not compatible with a benzoate group. 


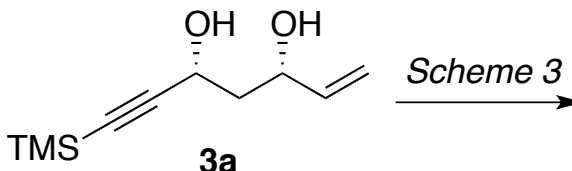

$3 a$

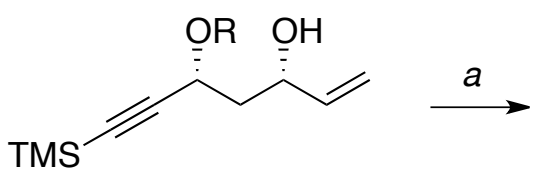

3c, $R=$ TBS

3d, $R=$ TBDPS

3e, $R=$ TIPS

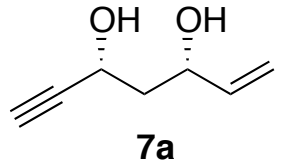

$7 a$

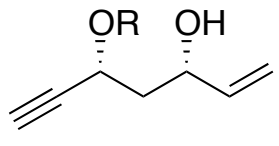

7c, $R=$ TBS

7d, $R=$ TBDPS

7e, $R=$ TIPS

7f, $R=B z$
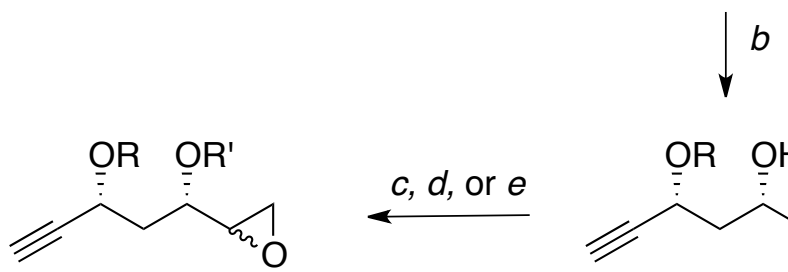

$c, d$, or $e$

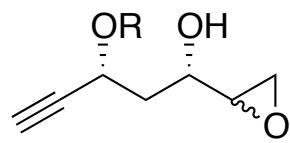

4g, $R=T B S, R^{\prime}=A c$

4c, $R=$ TBS

4h, $R=$ TBS, $R^{\prime}=$ TBDPS

4d, $R=$ TBDPS

$4 i, R=$ TBDPS, $R^{\prime}=$ TBS

4e, $R=$ TIPS

$4 j, R=$ TIPS, $R^{\prime}=A c$

4f, $R=B z$

4k, $R=B z, R^{\prime}=$ TBS

(a) 3c, 3d or 3e, $\mathrm{K}_{2} \mathrm{CO}_{3}(0.25-0.5$ equiv), $\mathrm{MeOH}, 1-3 \mathrm{~h}, \mathrm{rt}, 7 \mathrm{c}: 99 \%$, 7d: $84 \%, 7 e: 95 \%$; (b) 7c-f, $m$-CPBA (2.5-6.0 equiv), $\mathrm{CH}_{2} \mathrm{Cl}_{2}, 2.5-15 \mathrm{~h}$, rt, 4c: 97\%, 4d: 99\%, 4e: 95\%, 4f: $87 \%$; (c) 4c or $4 \mathbf{4 e}, \mathrm{Ac}_{2} \mathrm{O}(1 . c$ equiv), $\mathrm{NEt}_{3}, \mathrm{CH}_{2} \mathrm{Cl}_{2}, 1 \mathrm{~h}, \mathrm{rt}, \mathbf{4 g}: 98 \%, 4 \mathbf{j}$ : 90\%; (d) 4c, TBDPSCl (2.0 equiv), imidazole, THF, rt, 48 h, $\mathbf{4 h}: 79 \%$; (e) $\mathbf{4 d}$ or $\mathbf{4 f}, \mathrm{TBSCl}(1.9-2.6$ equiv), imidazole, THF, rt, 24 h, 4i: $71 \%$, 4k: $67 \%$.

\section{Scheme 4}

With epoxides $\mathbf{4 g - k}$ in hand, we attempted to bring about their Ti(III)-mediated cyclization by treatment with $\mathrm{Cp}_{2} \mathrm{TiCl}_{2}$ in the presence of an excess of a metal $\mathrm{M}$ such as $\mathrm{Zn}$ or $\mathrm{Mn}$ (Scheme 5). In this type of reaction the metal reduces $\mathrm{Cp}_{2} \mathrm{TiCl}_{2}$ to a $\mathrm{Cp}_{2} \mathrm{TiCl}$. radical $(\mathbf{8})$. Reaction of $\mathbf{8}$ with the corresponding epoxide 4 generates the titanocene(IV) $\beta$-alkoxy carbon radical 9 that gives rise to a cyclic vinyl radical 10. This radical can then be quenched either by a hydrogen donor or by another Ti(III) radical to afford 11 or $12\left(\mathrm{X}=\mathrm{H}\right.$ or $\mathrm{Cp}_{2} \mathrm{TiCl}$, respectively). Protonolysis of 11/12 should give methylene cyclopentane 5 . Although this reaction can be catalytic in $\mathrm{Cp}_{2} \mathrm{TiCl}_{2}$, Ziegler ${ }^{12}$ described the cyclization of epoxide $\mathbf{4 b}$ 
using an excess of $\mathrm{Cp}_{2} \mathrm{TiCl}_{2}$. Under these conditions, however, we could not reproduce the reported yield. When epoxide $\mathbf{4 b}$ was treated with $\mathrm{Cp}_{2} \mathrm{TiCl}_{2}$ in the presence of an excess of $\mathrm{Zn}$ following the described procedure, the methylene cyclopropane $\mathbf{5 b}\left(\mathrm{PG}_{1}=\mathrm{PG}_{2}=\mathrm{TBS}, \mathrm{PG}_{3}=\mathrm{H}\right)$ was obtained with good diastereoselectivity but in a yield of only $30 \%$.

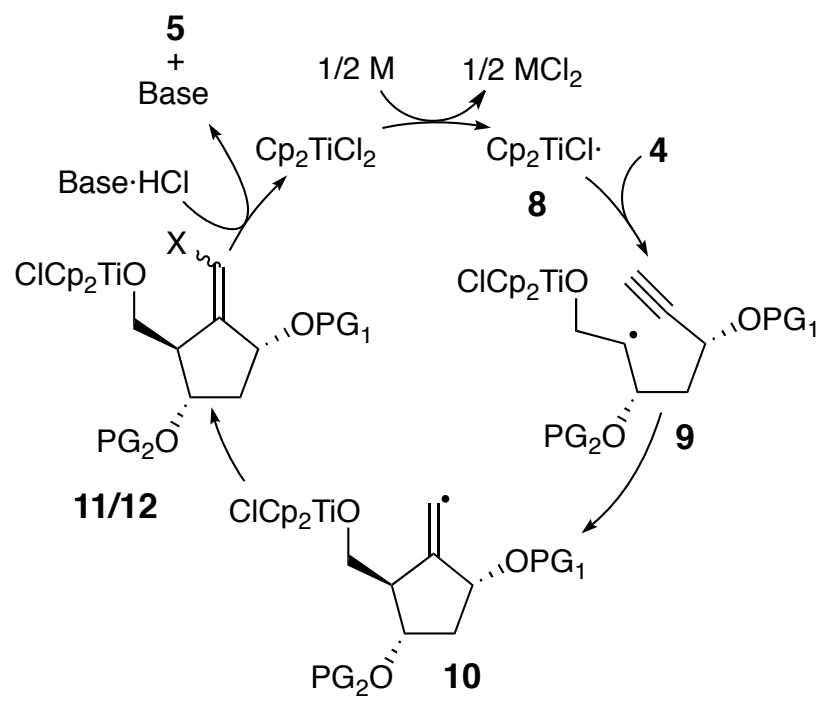

\section{Scheme 5}

Fortunately, yields could be increased to $50 \%$ by replacing the aqueous $\mathrm{H}_{2} \mathrm{SO}_{4}$ work-up with a treatment with saturated $\mathrm{NH}_{4} \mathrm{Cl}$ (entry 1, Table 2). Under these optimized conditions cyclizations of epoxides $\mathbf{4 g - k}$ were carried out. The results are summarized in Table 2 and it can be seen that the election of the propargylic alcohol protecting group (R) is critical. TBS provided the best yields (entries 1, 2, and 5) when compared with TIPS and TBDPS (entries 3 and 6) and better selectivity than the benzoyl group (entry 4). In sharp contrast, protection of the allylic alcohol has little effect on yield or selectivity (entries 1, 2, and 5). These results suggested $\mathbf{4 b}, \mathbf{4 g}$ and $\mathbf{4 h}$ to be the most promising candidates for cyclization. We finally chose the transformation of $\mathbf{4 g}$ to $\mathbf{5 g}$ as the key step of the synthesis because it provided better overall yield from diol 3a and allowed differentiation of the protected alcohols.

TABLE 2. Stoichiometric cyclization of propargylic epoxides $4 \mathrm{~b}$ and $4 \mathrm{~g}-\mathrm{k}$. 


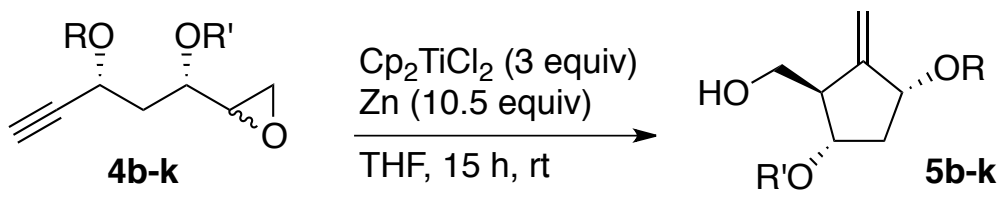

\begin{tabular}{|c|c|c|c|c|c|c|}
\hline Entry & Epoxide & R & R' & Product & Yield (\%) & $\mathrm{dr}^{\mathrm{a}}$ \\
\hline 1 & $\mathbf{4 b}$ & TBS & TBS & $\mathbf{5 b}$ & 50 & $95: 5$ \\
\hline 2 & $\mathbf{4 h}$ & TBS & TBDPS & $\mathbf{5 h}$ & 43 & $>97: 3$ \\
\hline 3 & $\mathbf{4 i}$ & TBDPS & TBS & $\mathbf{5 i}$ & $<10^{\mathrm{a}}$ & n. d. \\
\hline 4 & $\mathbf{4 k}$ & Bz & TBS & $\mathbf{5 k}$ & 49 & $90: 10$ \\
\hline 5 & $\mathbf{4 g}$ & TBS & Ac & $\mathbf{5 g}$ & 40 & $96: 4$ \\
\hline 6 & $\mathbf{4 j}$ & TIPS & Ac & $\mathbf{5 j}$ & 0 & - \\
\hline
\end{tabular}

${ }^{a}$ Not chromatographically isolated. Yield estimated from ${ }^{1} \mathrm{H}-\mathrm{NMR}$.

The Ti-catalytic version of the cyclization was also explored in an attempt to improve the process. In the stoichiometric process $\mathbf{1 1} / \mathbf{1 2}$ are cleaved in the final step by treatment with saturated $\mathrm{NH}_{4} \mathrm{Cl}$. In the catalytic version an alternative proton source is required to cleave 11/12 and regenerate the catalyst. Gansäuer ${ }^{16}$ described the use of collidine hydrochloride as the most convenient reagent for doing so.

After careful optimization of the reaction conditions we were able to carry out the cyclization of $\mathbf{4 g}$ to 5g using 20\% catalyst and collidine hydrochloride as proton source with excellent selectivity and comparable yields to the stoichiometric version (Table 3, entries 1 and 4). Mn provides similar yields to $\mathrm{Zn}$ but requires less metal to generate $\mathbf{8}$.

On the other hand, we found that the use of trimethylsilylcollidinium chloride ${ }^{17}$ instead of collidine hydrochloride (entries 2 and 5) while not improving yields did improve the reproducibility of the process at larger scales. A further improvement was achieved by introducing Vaska's complex, $\operatorname{IrCl}(\mathrm{CO})\left(\mathrm{PPh}_{3}\right)_{2}$ in the presence of $\mathrm{H}_{2}$ as hydrogen donor ${ }^{18}$ (entries 3, 6, and 7).

TABLE 3. Catalytic cyclization of $4 \mathrm{~g}$ to cyclopentane $5 \mathrm{~g}$. 


$$
\begin{aligned}
& \mathrm{Cp}_{2} \mathrm{TiCl}_{2}(20 \% \mathrm{~mol}) \\
& \mathbf{4 g} \stackrel{\mathrm{Zn} \text { (3 equiv) or } \mathrm{Mn}(2 \text { equiv) }}{\longrightarrow} \mathbf{5 g} \\
& \text { collidine (8 equiv) / TMSCI (4 equiv) } \\
& \operatorname{IrCl}(\mathrm{CO})\left(\mathrm{PPh}_{3}\right)_{2} / \mathrm{H}_{2} \text { (4 bar) }
\end{aligned}
$$

\begin{tabular}{|c|c|c|c|c|}
\hline Entry & $\mathrm{M}$ & Collidinium Salt & $\mathrm{IrCl}(\mathrm{CO})\left(\mathrm{PPh}_{3}\right)_{2}$ & Yield (\%) \\
\hline 1 & $\mathrm{Zn}$ & Collidine $\mathrm{HCl}$ & - & 36 \\
\hline 2 & $\mathrm{Zn}$ & Collidine/TMSCl & - & 38 \\
\hline 3 & $\mathrm{Zn}$ & Collidine/TMSCl & $5 \%$ & 51 \\
\hline 4 & $\mathrm{Mn}$ & Collidine·HCl & - & 42 \\
\hline 5 & $\mathrm{Mn}$ & Collidine/TMSCl & - & 36 \\
\hline 6 & $\mathrm{Mn}$ & Collidine/TMSCl & $5 \%$ & 49 \\
\hline 7 & $\mathrm{Mn}$ & Collidine/TMSCl & $10 \%$ & 58 \\
\hline
\end{tabular}

The last step in the preparation of the carbocyclic moiety of Entecavir was the protection of the primary hydroxyl group of $\mathbf{5 g}$ in the form of a $p$-nitrobenzoyl ester $\mathbf{5 l}$. The election of this protecting group is important because $\mathbf{5 l}$ can be crystallized and purified. By this means chromatographic purifications of intermediates $\mathbf{3 a}$ to $\mathbf{5 g}$ (which are oils) can be avoided (Scheme 6). 


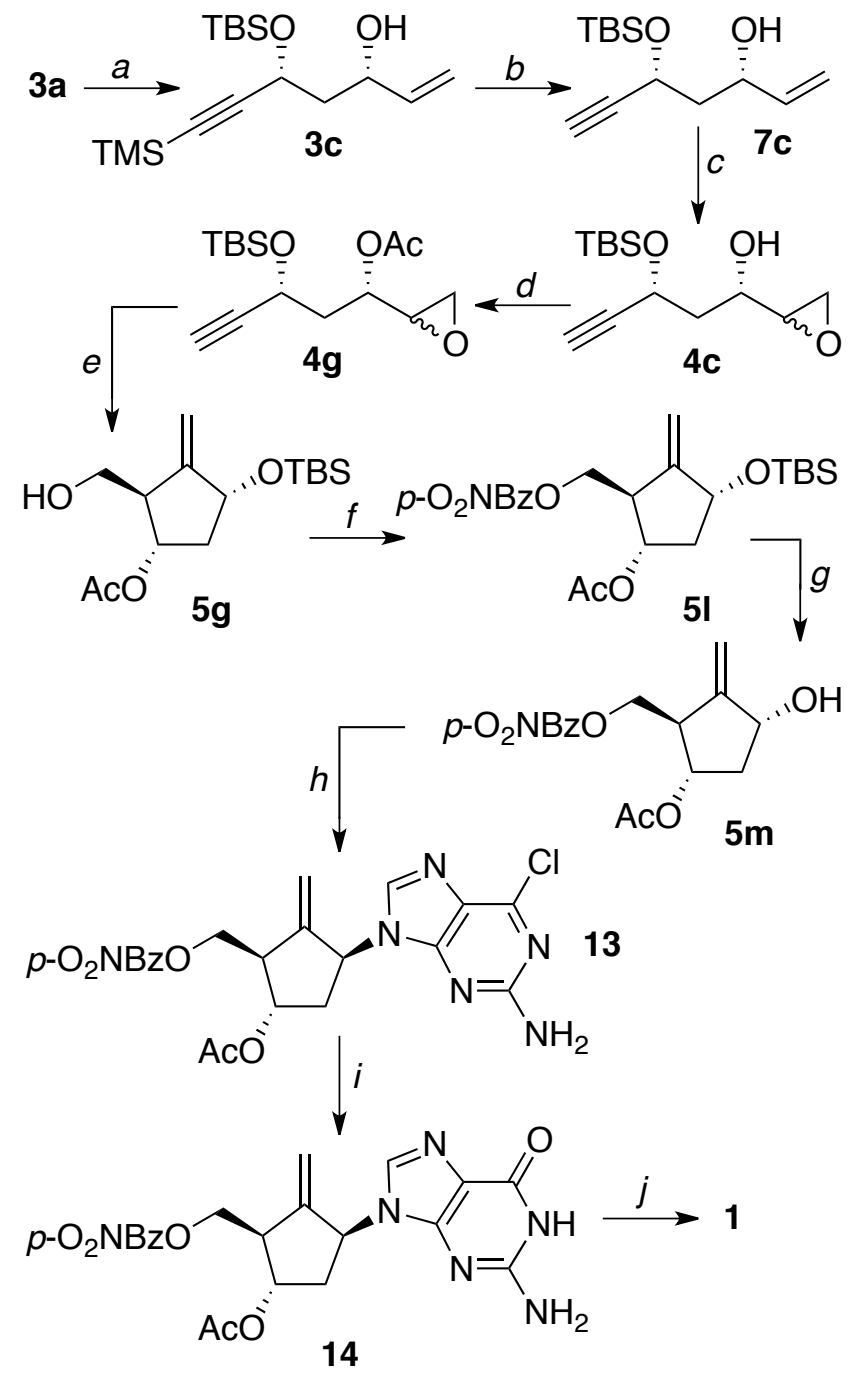

(a) TBSCI (1.1 equiv), imidazole, THF, 6 h, rt, 69\%; (b) $\mathrm{K}_{2} \mathrm{CO}_{3}$ cat., $\mathrm{MeOH}, 1 \mathrm{~h}$, rt, 95\%; (c) $m-\mathrm{CPBA}, \mathrm{CH}_{2} \mathrm{Cl}_{2}$, 15 h, rt, 95\%; (d) $\mathrm{Ac}_{2} \mathrm{O}, \mathrm{NEt}_{3}$, DMAP cat., $\mathrm{CH}_{2} \mathrm{Cl}_{2}, 1 \mathrm{~h}$, rt, 95\%; (e) $\mathrm{Cp}_{2} \mathrm{TiCl}_{2} 20 \%$ mol., $\operatorname{IrCl}(\mathrm{CO})\left(\mathrm{PPh}_{3}\right)_{2} 10 \%$ mol., Mn (2 equiv), collidine, TMSCl, $\mathrm{H}_{2}$ (4 bar), THF, 4 h, rt, 58\%; (f) $p-\mathrm{O}_{2} \mathrm{NBzCl}, \mathrm{NEt}_{3}, \mathrm{CH}_{2} \mathrm{Cl}_{2}, 1.5 \mathrm{~h}, \mathrm{rt}, 74 \%$. (g) $5 \%$ (+)-CSA, MeOH, 3 h, rt, 89\%. (h) 2-amino-6chloropurine, DIAD, $\mathrm{PPh}_{3}, \mathrm{THF}, 3 \mathrm{~h},-10^{\circ} \mathrm{C}, 61 \%$. (i) $\mathrm{HCOOH}, 50{ }^{\circ} \mathrm{C}, 9 \mathrm{~h}, 92 \%$. (j) $\mathrm{MeONa}, \mathrm{MeOH}, 1 \mathrm{~h}$, rt, $72 \%$.

\section{Scheme 6}

Final conversion of $\mathbf{5 1}$ to pharmaceutical-grade Entecavir was straightforward. Selective acidic deprotection of the TBS ether followed by Mitsunobu reaction with 2-amino-6-chloropurine ${ }^{6 x}$ led to the chloroderivative 13 that was transformed into protected Entecavir 14 by treatment with formic acid. Saponification of $\mathbf{1 4}$ then gave Entecavir of pharmaceutical grade. Reversal of the order of the last two 
steps decreased the overall yield and increased the formation of impurities that impeded the crystallization of the final product as did the direct acid hydrolysis of both of the esters and the chloropurine moiety.

\section{Conclusions}

A straightforward synthesis of Entecavir was achieved in 11 steps from commercially available starting materials. The cyclopentane skeleton was prepared from acyclic precursors by a boron-aldol reaction and a $\mathrm{Ti}(\mathrm{III})$-catalyzed cyclization of an epoxide to an alkyne as key steps. The carbocylic structure obtained in this way was attached to a purine moiety by a Mitsunobu reaction. It is worth mentioning that the use of the $p$-nitrobenzoyl group in the final steps allows purification by crystallization thus avoiding chromatography and making the synthesis amenable to scale-up. The selective hydrolysis of the 6-chloropurine unit with formic acid is also essential in order to facilitate the crystallization of the final product.

\section{Experimental Section}

All reactions involving moisture- or air-sensitive reagents were performed in oven-dried glassware under $\mathrm{N}_{2}$. Chemical shifts $(\delta)$ were quoted in parts per million and referenced for ${ }^{1} \mathrm{H}$ NMR to internal TMS (for $\mathrm{CDCl}_{3}$ ) or residual solvent peak $\delta 2.50 \mathrm{ppm}$ (for DMSO- $d_{6}$ ). ${ }^{13} \mathrm{C} \mathrm{NMR}$ was referenced to $\mathrm{CDCl}_{3}(\delta 77.0 \mathrm{ppm})$ or DMSO- $d_{6}(\delta 39.5 \mathrm{ppm})$. Column chromatography was performed on silica gel (Merck 230-400 mesh). HRMS analyses were recorded on a LC/MSD-TOF mass spectrometer.

(3S,5R)-7-(Trimethylsilyl)hept-1-en-6-yne-3,5-diol (3a). NEt $_{3}(11.60 \mathrm{~mL}, 85 \mathrm{mmol})$ was added to a stirred solution of (+)-DIPCl (90-105\%) (25.000 g, $78 \mathrm{mmol})$ in anhydrous THF (40 mL) under $\mathrm{N}_{2}$ at 0 ${ }^{\circ} \mathrm{C}$. 4-Trimethylsilyl-3-butyn-2-one $(98 \%, 9.78 \mathrm{~g}, 70 \mathrm{mmol})$ was added dropwise and the mixture was

stirred for $2 \mathrm{~h}$ at $-5{ }^{\circ} \mathrm{C}-0{ }^{\circ} \mathrm{C}$. The solution was cooled to $-78{ }^{\circ} \mathrm{C}$ and a solution of acrolein $(90 \%, 7.62$ $\mathrm{mL}, 103 \mathrm{mmol})$ in anhydrous THF (20 mL) was added slowly and the mixture was stirred for $1 \mathrm{~h}$ at -78 ${ }^{\circ} \mathrm{C}$. A $2 \mathrm{M}$ solution of $\mathrm{LiBH}_{4}$ in hexanes $(53 \mathrm{~mL}, 106 \mathrm{mmol})$ was added slowly and the mixture was stirred for a further $1 \mathrm{~h}$ at $-78{ }^{\circ} \mathrm{C}$. After careful quenching with saturated $\mathrm{NH}_{4} \mathrm{Cl}(40 \mathrm{~mL})$ at $-78{ }^{\circ} \mathrm{C}$ the 
mixture was allowed to warm to rt over $30 \mathrm{~min}$. After partitioning between $\mathrm{H}_{2} \mathrm{O}(40 \mathrm{~mL})$ and MTBE (90 $\mathrm{mL})$ the aqueous layer was extracted with $\operatorname{MTBE}(25 \mathrm{~mL})$. The organic phases were combined and dried $\left(\mathrm{MgSO}_{4}\right)$. Solvent removal afforded a pale yellow oil (62 g). THF: $\mathrm{H}_{2} \mathrm{O}(3: 1,80 \mathrm{~mL})$ was added under $\mathrm{N}_{2}$ at $\mathrm{rt}$ followed by $\mathrm{NaOAc}(4.40 \mathrm{~g}, 54 \mathrm{mmol})$ and the mixture was cooled to $0{ }^{\circ} \mathrm{C} . \mathrm{H}_{2} \mathrm{O}_{2}(30 \%$, $30 \mathrm{~mL}, 5$ equiv) was added dropwise over $10 \mathrm{~min}$ and the mixture was stirred for a further $10 \mathrm{~min}$ at 0 ${ }^{\circ} \mathrm{C}$ and $30 \mathrm{~min}$ at $\mathrm{rt}$. After cooling to $0{ }^{\circ} \mathrm{C}$ a saturated solution of $\mathrm{Na}_{2} \mathrm{~S}_{2} \mathrm{O}_{3}(30 \mathrm{~mL})$ was added slowly and the mixture was stirred for $10 \mathrm{~min}$ at $0{ }^{\circ} \mathrm{C}$ and $15 \mathrm{~min}$ at $\mathrm{rt} . \mathrm{H}_{2} \mathrm{O}(20 \mathrm{~mL})$ and MTBE $(35 \mathrm{~mL})$ were added and the organic phase was decanted. The aqueous layer was extracted with MTBE (10 mL) and the combined organic extracts were dried $\left(\mathrm{MgSO}_{4}\right)$. Solvent removal gave a clear oil (49.2 g) that was purified by flash chromatography [silica gel, hexanes-AcOEt, from 90:10 to 60:40 (gradient elution)] to give $9.130 \mathrm{~g}$ of a mixture of diols (er 80:20; syn/anti 90:10).

Recrystallization from hexanes afforded the product as a white crystalline solid (3a, ${ }^{9 \mathrm{a}} 5.2 \mathrm{~g}, 37 \%$ overall yield, er 98\%). Mp 80-82 ${ }^{\circ} \mathrm{C} .[\alpha]_{\mathrm{D}}^{25}+2.3$ (c 1.0, $\left.\mathrm{CHCl}_{3}\right)$. IR (film): 3349, 2956, 2922, 2899 , $2176 \mathrm{~cm}^{-1} .{ }^{1} \mathrm{H} \mathrm{NMR}\left(\mathrm{CDCl}_{3}, 400 \mathrm{MHz}\right): \delta 5.90(\mathrm{ddd}, J=17.2,10.4,5.9 \mathrm{~Hz}, 1 \mathrm{H}), 5.29(\mathrm{ddd}, J=17.2$, 1.4, $1.3 \mathrm{~Hz}, 1 \mathrm{H}), 5.14(\mathrm{ddd}, J=10.4,1.4,1.3 \mathrm{~Hz}, 1 \mathrm{H}), 4.64(\mathrm{dd}, J=7.9,5.2 \mathrm{~Hz}, 1 \mathrm{H}), 4.43-4.37(\mathrm{~m}$, 1H), $2.80(\mathrm{bs}, 1 \mathrm{H}), 2.46(\mathrm{bs}, 1 \mathrm{H}), 2.03-1.89(\mathrm{~m}, 2 \mathrm{H}), 0.18(\mathrm{~s}, 9 \mathrm{H}) .{ }^{13} \mathrm{C} \mathrm{NMR}\left(\mathrm{CDCl}_{3}, 101 \mathrm{MHz}\right): \delta$ 140.1, 115.1, 106.1, 89.9, 72.1, 62.0, 44.0, -0.1. HRMS (ESI): $m / z$ calcd. for $\mathrm{C}_{10} \mathrm{H}_{18} \mathrm{O}_{2} \mathrm{SiNa}^{+}[\mathrm{M}+\mathrm{Na}]^{+}$ 221.0969; found 221.0974.

$(3 S, 5 R)-3,5-B i s($ tert-butyldimethylsilyloxy)-7-(trimethylsilyl)hept-1-en-6-yne (3b). A solution of TBSCl $(0.800 \mathrm{~g}, 5.30 \mathrm{mmol})$ in anhydrous $\mathrm{CH}_{2} \mathrm{Cl}_{2}(5 \mathrm{~mL})$ was added dropwise to a solution of diol 3a $(0.500 \mathrm{~g}, 2.52 \mathrm{mmol})$ and imidazole $(0.377 \mathrm{~g}, 5.54 \mathrm{mmol})$ in anhydrous $\mathrm{CH}_{2} \mathrm{Cl}_{2}(5 \mathrm{~mL})$ at $0{ }^{\circ} \mathrm{C}$ under $\mathrm{N}_{2}$. The mixture was allowed to warm to $\mathrm{rt}$ and was stirred for $15 \mathrm{~h}$. A $22 \%$ solution of $\mathrm{NH}_{4} \mathrm{Cl}(5 \mathrm{~mL})$ was added slowly and the mixture was stirred for $10 \mathrm{~min}$. The mixture was partitioned and the aqueous phase was extracted with $\mathrm{CH}_{2} \mathrm{Cl}_{2}(5 \mathrm{~mL})$. The organic phase was dried $\left(\mathrm{MgSO}_{4}\right)$ and the solvent was removed affording an oil that was purified by flash chromatography (silica gel, hexanes-AcOEt 95:5) to 
give $1.030 \mathrm{~g}(96 \%)$ of the title compound ${ }^{9 \mathrm{a}}(\mathbf{3 b})$ as a yellow oil. $[\alpha]_{\mathrm{D}}{ }^{25}+21.6\left(c 1.0, \mathrm{CHCl}_{3}\right)$. IR (film): 3071, 2952, 2930, 2897, 2858, $2172 \mathrm{~cm}^{-1} .{ }^{1} \mathrm{H}$ NMR $\left(\mathrm{CDCl}_{3}, 300 \mathrm{MHz}\right): \delta 5.81$ (ddd, $J=17.2,10.3,6.4$ $\mathrm{Hz}, 1 \mathrm{H}), 5.15(\mathrm{dt}, J=17.2,1.4 \mathrm{~Hz}, 1 \mathrm{H}), 5.04(\mathrm{dt}, J=10.3,1.4 \mathrm{~Hz}, 1 \mathrm{H}), 4.46(\mathrm{dd}, J=7.7,6.4 \mathrm{~Hz}, 1 \mathrm{H})$, 4.33-4.24 (m, 1H), $1.90(\mathrm{ddd}, J=13.2,8.1,6.7 \mathrm{~Hz}, 1 \mathrm{H}), 1.74(\mathrm{ddd}, J=13.2,7.7,5.2 \mathrm{~Hz}, 1 \mathrm{H}), 0.90(\mathrm{~s}$, 9H), $0.89(\mathrm{~s}, 9 \mathrm{H}), 0.16(\mathrm{~s}, 9 \mathrm{H}), 0.13(\mathrm{~s}, 3 \mathrm{H}), 0.10(\mathrm{~s}, 3 \mathrm{H}), 0.07(\mathrm{~s}, 3 \mathrm{H}), 0.03(\mathrm{~s}, 3 \mathrm{H}) .{ }^{13} \mathrm{C} \mathrm{NMR}\left(\mathrm{CDCl}_{3}\right.$, $101 \mathrm{MHz}): \delta$ 141.3, 114.4, 107.4, 89.5, 71.3, 61.3, 46.9, 26.0, 25.9, 18.4, 18.3, 0.0, -4.1, -4.3, -4.8, -4.8. HRMS (ESI): $m / z$ calcd. for $\mathrm{C}_{22} \mathrm{H}_{47} \mathrm{O}_{2} \mathrm{Si}_{3}{ }^{+}[\mathrm{M}+\mathrm{H}]^{+} 427.2878$; found 427.2867 .

(3S,5R)-5-(tert-Butyldimethylsilyloxy)-7-(trimethylsilyl)hept-1-en-6-yn-3-ol (3c). A solution of TBSCl (4.180 g, $27.73 \mathrm{mmol})$ in anhydrous THF $(20 \mathrm{~mL})$ was added dropwise to a solution of diol 3a $(5.000 \mathrm{~g}, 25.21 \mathrm{mmol})$ and imidazole $(2.060 \mathrm{~g}, 30.25 \mathrm{mmol})$ in anhydrous THF $(60 \mathrm{~mL})$ at $0{ }^{\circ} \mathrm{C}$ under $\mathrm{N}_{2}$, and the mixture was allowed to warm to rt and was stirred for $5 \mathrm{~h}$. A $22 \%$ solution of $\mathrm{NH}_{4} \mathrm{Cl}(25$ $\mathrm{mL}$ ) was added slowly and the mixture was stirred for $10 \mathrm{~min}$. The mixture was partitioned and the organic phase was dried $\left(\mathrm{MgSO}_{4}\right)$ and the solvent was removed affording an oil that was purified by flash chromatography [silica gel, hexanes-AcOEt, from 97:3 to 80:20 (gradient elution)] to give $5.123 \mathrm{~g}$ $(65 \%)$ of the title compound ${ }^{9 \mathrm{a}}(\mathbf{3 c})$ as a pale yellow oil. $[\alpha]_{\mathrm{D}}{ }^{25}+39.9$ (c 1.0, $\left.\mathrm{CHCl}_{3}\right)$. IR (film): 3424 , 3081, 2958, 2930, 2898, 2858, $2172 \mathrm{~cm}^{-1} .{ }^{1} \mathrm{H}$ NMR $\left(\mathrm{CDCl}_{3}, 300 \mathrm{MHz}\right): \delta 5.86(\mathrm{ddd}, J=17.2,10.5,5.6$ $\mathrm{Hz}, 1 \mathrm{H}), 5.28(\mathrm{dt}, J=17.2,1.5 \mathrm{~Hz}, 1 \mathrm{H}), 5.11(\mathrm{dt}, J=10.5,1.5 \mathrm{~Hz}, 1 \mathrm{H}), 4.59(\mathrm{dd}, J=7.9,5.3 \mathrm{~Hz}, 1 \mathrm{H})$, 4.42-4.30 (m, 1H), $2.98(\mathrm{~d}, J=2.4 \mathrm{~Hz}, 1 \mathrm{H}), 1.99-1.86(\mathrm{~m}, 2 \mathrm{H}), 0.91(\mathrm{~s}, 9 \mathrm{H}), 0.19(\mathrm{~s}, 3 \mathrm{H}), 0.16(\mathrm{~s}, 12 \mathrm{H})$. ${ }^{13} \mathrm{C} \mathrm{NMR}\left(\mathrm{CDCl}_{3}, 101 \mathrm{MHz}\right): \delta 140.3,114.6,106.7,90.3,71.5,62.9,45.1,25.9,18.2,-0.2,-4.1,-4.8$. HRMS (ESI): $m / z$ calcd. for $\mathrm{C}_{16} \mathrm{H}_{33} \mathrm{O}_{2} \mathrm{Si}_{2}{ }^{+}[\mathrm{M}+\mathrm{H}]^{+}$313.2014; found 313.2005 .

(3S,5R)-5-(tert-Butyldiphenylsilyloxy)-7-(trimethylsilyl)hept-1-en-6-yn-3-ol (3d). TBDPSCl (1.57 $\mathrm{mL}, 6.10 \mathrm{mmol})$ was added dropwise to a solution of diol 3a $(1.000 \mathrm{~g}, 5.04 \mathrm{mmol})$ and imidazole $(0.481$ $\mathrm{g}, 7.06 \mathrm{mmol})$ in anhydrous THF $(9.5 \mathrm{~mL})$ at $0{ }^{\circ} \mathrm{C}$ under $\mathrm{N}_{2}$, and the mixture was allowed to warm to $\mathrm{rt}$ and was stirred for $5 \mathrm{~h}$. A $22 \%$ solution of $\mathrm{NH}_{4} \mathrm{Cl}(5 \mathrm{~mL})$ was added slowly and the mixture was stirred for $10 \mathrm{~min}$. The mixture was partitioned and the organic phase was dried $\left(\mathrm{MgSO}_{4}\right)$, and the solvent was 
removed affording an oil that was purified by flash chromatography [silica gel, hexanes-AcOEt, from 95:5 to 90:10 (gradient elution)] to give $1.363 \mathrm{~g}(62 \%)$ of the title compound (3d) as a pale yellow oil. $[\alpha]_{\mathrm{D}}^{25}+62.5\left(c 1.0, \mathrm{CHCl}_{3}\right)$. IR (film): 3446, 3071, 2958, 2931, 2894, $2857 \mathrm{~cm}^{-1} .{ }^{1} \mathrm{H}$ NMR $\left(\mathrm{CDCl}_{3}, 400\right.$ MHz): $\delta$ 7.77-7.66 (m, 4H), 7.45-7.33 (m, 6H), $5.84(\mathrm{ddd}, J=17.2,10.5,5.6 \mathrm{~Hz}, 1 \mathrm{H}), 5.23(\mathrm{dt}, J=$ $17.2,1.5 \mathrm{~Hz}, 1 \mathrm{H}), 5.07(\mathrm{dt}, J=10.5,1.5 \mathrm{~Hz}, 1 \mathrm{H}), 4.54(\mathrm{t}, J=6.3 \mathrm{~Hz}, 1 \mathrm{H}), 4.51-4.43(\mathrm{~m}, 1 \mathrm{H}), 2.64(\mathrm{~d}, J$ $=3.4 \mathrm{~Hz}, 1 \mathrm{H}), 2.01-1.85(\mathrm{~m}, 2 \mathrm{H}), 1.06(\mathrm{~s}, 9 \mathrm{H}), 0.10(\mathrm{~s}, 9 \mathrm{H}) .{ }^{13} \mathrm{C} \mathrm{NMR}\left(\mathrm{CDCl}_{3}, 101 \mathrm{MHz}\right): \delta 140.4$, 136.2, 136.0, 134.9, 133.6, 133.3, 130.0, 129.8, 129.7, 127.8, 127.7, 127.5, 114.5, 106.2, 91.3, 70.6, 62.8, 45.2, 27.0, 26.7, 19.4, -0.4. HRMS (ESI): $\mathrm{m} / z$ calcd. for $\mathrm{C}_{26} \mathrm{H}_{37} \mathrm{O}_{2} \mathrm{Si}_{2}{ }^{+}[\mathrm{M}+\mathrm{H}]^{+}$437.2327; found 437.2325 .

(3S,5R)-5-(Triisopropylsilyloxy)-7-(trimethylsilyl)hept-1-en-6-yn-3-ol (3e). TIPSCl $\quad(5.20 \mathrm{~mL}$, $30.25 \mathrm{mmol})$ was added dropwise to a solution of diol 3a (5.000 g, $25.21 \mathrm{mmol})$ and imidazole (2.230 g, $32.77 \mathrm{mmol})$ in anhydrous THF $(40 \mathrm{~mL})$ at $0{ }^{\circ} \mathrm{C}$ under $\mathrm{N}_{2}$, and the mixture was allowed to warm to $\mathrm{rt}$ and was stirred for $15 \mathrm{~h}$. A $22 \%$ solution of $\mathrm{NH}_{4} \mathrm{Cl}(20 \mathrm{~mL})$ was added slowly and the mixture was stirred for $10 \mathrm{~min}$. The mixture was partitioned and the organic phase was extracted with MTBE $(2 \times 20$ $\mathrm{mL})$. The combined organic phases were dried $\left(\mathrm{MgSO}_{4}\right)$, and the solvent was removed affording an oil that was purified by flash chromatography [silica gel, hexanes-AcOEt, from 97:3 to 80:20 (gradient elution)] to give $6.173 \mathrm{~g}(69 \%)$ of the title compound as a pale yellow oil. $[\alpha]_{\mathrm{D}}^{25}+23.5\left(c 0.6, \mathrm{CHCl}_{3}\right)$. IR (film): 3421, 3074, 2944, 2894, 2867, $2167 \mathrm{~cm}^{-1} .{ }^{1} \mathrm{H}$ NMR $\left(\mathrm{CDCl}_{3}, 300 \mathrm{MHz}\right): \delta 5.89$ (ddd, $J=17.2$, $10.5,5.6 \mathrm{~Hz}, 1 \mathrm{H}), 5.28(\mathrm{dt}, J=17.2,1.5 \mathrm{~Hz}, 1 \mathrm{H}), 5.11(\mathrm{dt}, J=10.5,1.5 \mathrm{~Hz}, 1 \mathrm{H}), 4.71(\mathrm{t}, J=6.4 \mathrm{~Hz}$, 1H), 4.49-4.41 (m, 1H), $2.92(\mathrm{~d}, J=2.7 \mathrm{~Hz}, 1 \mathrm{H}), 1.95-1.89(\mathrm{~m}, 2 \mathrm{H}), 1.27-1.13(\mathrm{~m}, 3 \mathrm{H}), 1.13-1.04(\mathrm{~m}$, 18H). ${ }^{13} \mathrm{C} \mathrm{NMR}\left(\mathrm{CDCl}_{3}, 101 \mathrm{MHz}\right): \delta 140.5,114.4,106.9,90.3,71.1,62.5,45.5,18.2,17.9,12.5,-0.2$. HRMS (ESI): $m / z$ calcd. for $\mathrm{C}_{19} \mathrm{H}_{39} \mathrm{O}_{2} \mathrm{Si}_{2}{ }^{+}[\mathrm{M}+\mathrm{H}]^{+} 355.2483$; found 355.2478.

(3S,5R)-Hept-1-en-6-yne-3,5-diol (7a). $\mathrm{K}_{2} \mathrm{CO}_{3}(0.348 \mathrm{~g}, 2.52 \mathrm{mmol})$ was added in one portion to a stirred solution of 3a $(1.000 \mathrm{~g}, 5.04 \mathrm{mmol})$ in anhydrous $\mathrm{MeOH}(10 \mathrm{~mL})$ at $\mathrm{rt}$ under $\mathrm{N}_{2}$. The mixture was then stirred for $1 \mathrm{~h}$. A buffer solution $(\mathrm{pH}=7,10 \mathrm{~mL})$ and $\mathrm{CH}_{2} \mathrm{Cl}_{2}(10 \mathrm{~mL})$ were added, the mixture 
was partitioned and the organic phase was dried $\left(\mathrm{MgSO}_{4}\right)$. Solvent removal gave the title compound $(7 \mathbf{a})^{12}$ as a yellow oil $0.628 \mathrm{~g}(98 \%) .[\alpha]_{\mathrm{D}}^{25}+5.8\left(c 1.0, \mathrm{CHCl}_{3}\right)$. IR (film): 3347, 3290, 3060, 2983, 2953, 2922, 2887, $2113 \mathrm{~cm}^{-1} .{ }^{1} \mathrm{H}$ NMR $\left(\mathrm{CDCl}_{3}, 400 \mathrm{MHz}\right): \delta 5.86(\mathrm{ddd}, J=17.2,10.4,6.0 \mathrm{~Hz}, 1 \mathrm{H})$, $5.26(\mathrm{dt}, J=17.2,1.4 \mathrm{~Hz}, 1 \mathrm{H}), 5.11(\mathrm{dt}, J=10.4,1.4 \mathrm{~Hz}, 1 \mathrm{H}), 4.61(\mathrm{ddd}, J=8.3,5.1,2.1 \mathrm{~Hz}, 1 \mathrm{H}), 4.41-$ $4.34(\mathrm{~m}, 1 \mathrm{H}), 2.75(\mathrm{bs}, 1 \mathrm{H}), 2.49(\mathrm{~d}, J=2.1 \mathrm{~Hz}, 1 \mathrm{H}), 2.35$ (bs, 1H), 2.03-1.84 (m, 2H). ${ }^{13} \mathrm{C}$ NMR $\left(\mathrm{CDCl}_{3}, 101 \mathrm{MHz}\right): \delta 140.1,115.2,84.5,73.3,72.0,61.3,43.9 . \mathrm{HRMS}(\mathrm{ESI}): \mathrm{m} / z$ calcd. for $\mathrm{C}_{7} \mathrm{H}_{10} \mathrm{NaO}_{2}^{+}[\mathrm{M}+\mathrm{Na}]^{+}$149.0573; found 149.0572.

(3S,5R)-3,5-Bis(tert-butyldimethylsilyloxy)hept-1-en-6-yne (7b). A solution of TBSCl (2.059 g, $13.60 \mathrm{mmol})$ in anhydrous $\mathrm{CH}_{2} \mathrm{Cl}_{2}(5 \mathrm{~mL})$ was added dropwise to a solution of diol $7 \mathbf{a}(0.820 \mathrm{~g}, 6.50$ mmol) and imidazole $(1.062 \mathrm{~g}, 15.60 \mathrm{mmol})$ in anhydrous $\mathrm{CH}_{2} \mathrm{Cl}_{2}(3 \mathrm{~mL})$ at $0{ }^{\circ} \mathrm{C}$ under $\mathrm{N}_{2}$, and the mixture was allowed to warm to rt and was stirred for $15 \mathrm{~h}$. A $22 \%$ solution of $\mathrm{NH}_{4} \mathrm{Cl}(5 \mathrm{~mL})$ was added slowly and the mixture was stirred for $10 \mathrm{~min}$. The mixture was partitioned and the aqueous phase was extracted with $\mathrm{CH}_{2} \mathrm{Cl}_{2}(2 \times 10 \mathrm{~mL})$. The combined organic phases were dried $\left(\mathrm{MgSO}_{4}\right)$ and the solvent was removed affording an oil that was purified by flash chromatography [silica gel, hexanes-AcOEt, from $97: 3$ to $80: 20$ (gradient elution)] to give $2.280 \mathrm{~g}(95 \%)$ of the title compound (7b) $)^{12}$ as a pale yellow oil. $[\alpha]_{\mathrm{D}}{ }^{25}+13.0\left(c 1.0, \mathrm{CHCl}_{3}\right)$. IR (film): 3306, 3093, 2958, 2930, 2887, $2858 \mathrm{~cm}^{-1} .{ }^{1} \mathrm{H}$ NMR $\left(\mathrm{CDCl}_{3}, 400 \mathrm{MHz}\right): \delta 5.81(\mathrm{ddd}, J=17.2,10.4,6.5 \mathrm{~Hz}, 1 \mathrm{H}), 5.17(\mathrm{dt}, J=17.2,1.2 \mathrm{~Hz}, 1 \mathrm{H}), 5.05(\mathrm{dt}, J$ $=10.4,1.2 \mathrm{~Hz}, 1 \mathrm{H}), 4.47(\mathrm{ddd}, J=8.2,6.5,2.0 \mathrm{~Hz}, 1 \mathrm{H}), 4.33-4.26(\mathrm{~m}, 1 \mathrm{H}), 2.42(\mathrm{~d}, J=2.0 \mathrm{~Hz}, 1 \mathrm{H})$, 1.99-1.74 (m, 2H), $0.91(\mathrm{~s}, 9 \mathrm{H}), 0.90(\mathrm{~s}, 9 \mathrm{H}), 0.14(\mathrm{~s}, 3 \mathrm{H}), 0.11(\mathrm{~s}, 3 \mathrm{H}), 0.07(\mathrm{~s}, 3 \mathrm{H}), 0.03(\mathrm{~s}, 3 \mathrm{H}) .{ }^{13} \mathrm{C}$ $\operatorname{NMR}\left(\mathrm{CDCl}_{3}, 101 \mathrm{MHz}\right): \delta 141.3,114.4,85.4,72.9,71.1,60.6,47.2,26.0,25.9,18.4,18.3,-4.1,-4.4,-$ 4.8, -4.9. HRMS (ESI): $m / z$ calcd. for $\mathrm{C}_{19} \mathrm{H}_{39} \mathrm{O}_{2} \mathrm{Si}_{2}{ }^{+}[\mathrm{M}+\mathrm{H}]^{+}$355.2483; found 355.2486.

(3S,5R)-5-(tert-Butyldimethylsilyloxy)hept-1-en-6-yn-3-ol (7c). $\mathrm{K}_{2} \mathrm{CO}_{3}(0.101 \mathrm{~g}, 0.73 \mathrm{mmol})$ was added in one portion to a stirred solution of $\mathbf{3 c}(0.455 \mathrm{~g}, 1.46 \mathrm{mmol})$ in anhydrous $\mathrm{MeOH}(4.5 \mathrm{~mL})$ at $\mathrm{rt}$ under $\mathrm{N}_{2}$ and the mixture was stirred for $1 \mathrm{~h}$. After solvent removal $\mathrm{CH}_{2} \mathrm{Cl}_{2}(10 \mathrm{~mL})$ was added to the residue and the solution was filtered and dried $\left(\mathrm{MgSO}_{4}\right)$. Solvent removal gave the title compound $(7 \mathrm{c})^{9 \mathrm{a}}$ 
as a pale yellow oil $(0.366 \mathrm{~g}, 99 \%) .[\alpha]_{\mathrm{D}}^{25}+32.7\left(c 1.0, \mathrm{CHCl}_{3}\right) . \mathrm{IR}$ (film): $3417,3311,3079,2956$, $2930,2886,2858,2109 \mathrm{~cm}^{-1} .\left(\mathrm{CDCl}_{3}, 300 \mathrm{MHz}\right): \delta 5.88(\mathrm{ddd}, J=17.2,10.4,5.7 \mathrm{~Hz}, 1 \mathrm{H}), 5.29(\mathrm{dt}, J=$ 17.2, $1.5 \mathrm{~Hz}, 1 \mathrm{H}), 5.12(\mathrm{dt}, J=10.4,1.5 \mathrm{~Hz}, 1 \mathrm{H}), 4.61(\mathrm{ddd}, J=7.8,5.8,2.1 \mathrm{~Hz}, 1 \mathrm{H}), 4.42-4.33(\mathrm{~m}$, 1H), $2.71(\mathrm{~d}, J=2.7 \mathrm{~Hz}, 1 \mathrm{H}), 2.47(\mathrm{~d}, J=2.1 \mathrm{~Hz}, 1 \mathrm{H}), 2.03-1.85(\mathrm{~m}, 2 \mathrm{H}), 0.92(\mathrm{~s}, 9 \mathrm{H}), 0.19(\mathrm{~s}, 3 \mathrm{H})$, $0.16(\mathrm{~s}, 3 \mathrm{H}) .{ }^{13} \mathrm{C} \mathrm{NMR}\left(\mathrm{CDCl}_{3}, 101 \mathrm{MHz}\right): \delta 140.3,114.8,84.9,73.5,71.2,62.0,45.2,25.9,18.2,-4.2,-$ 4.9. HRMS (ESI): $m / z$ calcd. for $\mathrm{C}_{13} \mathrm{H}_{24} \mathrm{NaO}_{2} \mathrm{Si}^{+}[\mathrm{M}+\mathrm{Na}]^{+}$263.1438; found 263.1431.

(3S,5R)-5-(tert-Butyldiphenylsilyloxy)hept-1-en-6-yn-3-ol (7d). $\mathrm{K}_{2} \mathrm{CO}_{3}(0.080 \mathrm{~g}, 0.57 \mathrm{mmol})$ was added in one portion to a stirred solution of $\mathbf{3 d}(0.500 \mathrm{~g}, 1.14 \mathrm{mmol})$ in anhydrous $\mathrm{MeOH}(5 \mathrm{~mL})$ at $\mathrm{rt}$ under $\mathrm{N}_{2}$ and the mixture was stirred for $3 \mathrm{~h}$. A buffer solution $(\mathrm{pH}=7,5 \mathrm{~mL})$ and MTBE $(15 \mathrm{~mL})$ were added, the mixture was partitioned and the organic phase was dried $\left(\mathrm{MgSO}_{4}\right)$. Solvent removal gave the title compound (7d) as a pale yellow oil $(0.350 \mathrm{~g}, 84 \%)$. $[\alpha]_{\mathrm{D}}{ }^{25}+34.3\left(c 1.0, \mathrm{CHCl}_{3}\right)$. IR (film): 3453 , $3303,3071,2956,2930,2891,2858 \mathrm{~cm}^{-1} .{ }^{1} \mathrm{H} \mathrm{NMR}\left(\mathrm{CDCl}_{3}, 400 \mathrm{MHz}\right): \delta$ 7.78-7.69 (m, 4H), 7.47-7.36 $(\mathrm{m}, 6 \mathrm{H}), 5.88-5.78(\mathrm{~m}, 1 \mathrm{H}), 5.22(\mathrm{dt}, J=17.2,1.4 \mathrm{~Hz}, 1 \mathrm{H}), 5.08(\mathrm{dt}, J=10.5,1.4 \mathrm{~Hz}, 1 \mathrm{H}), 4.60(\mathrm{td}, J=$ 6.5, 2.1 Hz, 1H), 4.47-4.39 (m, 1H), $2.35(\mathrm{~d}, J=2.1 \mathrm{~Hz}, 1 \mathrm{H}), 2.15(\mathrm{~m}, 1 \mathrm{H}), 1.96-1.90(\mathrm{~m}, 2 \mathrm{H}), 1.10(\mathrm{~s}$, 9H). ${ }^{13} \mathrm{C} \mathrm{NMR}\left(\mathrm{CDCl}_{3}, 101 \mathrm{MHz}\right): \delta 140.5,136.2,136.0,133.3,133.3,130.4,129.9,127.8,127.6$, 114.6, 84.5, 74.2, 70.3, 62.1, 45.3, 27.0, 19.4. HRMS (ESI): $m / z$ calcd. for $\mathrm{C}_{23} \mathrm{H}_{28} \mathrm{NaO}_{2} \mathrm{Si}^{+}[\mathrm{M}+\mathrm{Na}]^{+}$ 387.1751; found 387.1752 .

(3S,5R)-5-(Triisopropylsilyloxy)hept-1-en-6-yn-3-ol (7e). $\mathrm{K}_{2} \mathrm{CO}_{3}(0.526 \mathrm{~g}, 3.81 \mathrm{mmol})$ was added in one portion to a stirred solution of $\mathbf{3 e}(6.000 \mathrm{~g}, 15.23 \mathrm{mmol})$ in anhydrous $\mathrm{MeOH}(50 \mathrm{~mL})$ at $\mathrm{rt}$ under $\mathrm{N}_{2}$ and the mixture was stirred for $1 \mathrm{~h}$. A buffer solution $(\mathrm{pH}=7,15 \mathrm{~mL})$ and MTBE $(15 \mathrm{~mL})$ were added, the mixture was partitioned and the organic phase was dried $\left(\mathrm{MgSO}_{4}\right)$. Solvent removal gave the title compound (7e) as a pale yellow oil $(4.084 \mathrm{~g}, 95 \%) .[\alpha]_{\mathrm{D}}{ }^{25}+15.7\left(c 1.0, \mathrm{CHCl}_{3}\right)$. IR (film): 3421,3311 , 3083, 2944, 2893, $2867 \mathrm{~cm}^{-1} .{ }^{1} \mathrm{H}$ NMR $\left(\mathrm{CDCl}_{3}, 300 \mathrm{MHz}\right): \delta 5.97-5.83(\mathrm{~m}, 1 \mathrm{H}), 5.29(\mathrm{ddd}, J=17.3$, 2.7, $1.4 \mathrm{~Hz}, 1 \mathrm{H}), 5.12(\mathrm{ddd}, J=10.4,2.6,1.4 \mathrm{~Hz}, 1 \mathrm{H}), 4.74(\mathrm{td}, J=6.7,2.1 \mathrm{~Hz}, 1 \mathrm{H}), 4.50-4.39(\mathrm{~m}, 1 \mathrm{H})$, $2.55(\mathrm{~d}, J=3.0 \mathrm{~Hz}, 1 \mathrm{H}), 2.49-2.46(\mathrm{~m}, 1 \mathrm{H}), 1.99-1.91(\mathrm{~m}, 2 \mathrm{H}), 1.24-1.06(\mathrm{~m}, 21 \mathrm{H}) .{ }^{13} \mathrm{C} \mathrm{NMR}\left(\mathrm{CDCl}_{3}\right.$, 
$101 \mathrm{MHz}): \delta 140.5,114.6,85.0,73.6,70.9,61.8,45.5,18.2,18.1,17.8,12.4$. HRMS (ESI): $\mathrm{m} / z$ calcd. for $\mathrm{C}_{16} \mathrm{H}_{31} \mathrm{O}_{2} \mathrm{Si}^{+}[\mathrm{M}+\mathrm{H}]^{+}$283.2088; found 283.2077.

(3R,5S)-5-Hydroxyhept-6-en-1-yn-3-yl benzoate (7f). $i$ - $\operatorname{Pr}_{2} \mathrm{NEt}(0.76 \mathrm{~mL}, 4.37 \mathrm{mmol})$ was added dropwise to a solution of $7 \mathbf{a}(0.460 \mathrm{~g}, 3.64 \mathrm{mmol})$ in anhydrous $\mathrm{CH}_{2} \mathrm{Cl}_{2}(9 \mathrm{~mL})$ at $0{ }^{\circ} \mathrm{C}$ under $\mathrm{N}_{2}$. $\mathrm{BzCl}$ $(0.46 \mathrm{~mL}, 3.96 \mathrm{mmol})$ was added dropwise at $0{ }^{\circ} \mathrm{C}$ and the mixture was warmed to $\mathrm{rt}$ and stirred for 15 h. $\mathrm{MeOH}(2 \mathrm{~mL})$ was added and the mixture was stirred for $10 \mathrm{~min}$. After solvent removal the resulting oily residue was purified by flash chromatography [silica gel, hexanes-AcOEt, from 90:10 to 80:20 (gradient elution)] to give the title compound (7f, as the major isomer in a 91:9 mixture of monobenzoylated regioisomers) as a pale yellow oil $(0.741 \mathrm{~g}, 86 \%)$. $[\alpha]_{\mathrm{D}}^{25}+26.0\left(c 1.0, \mathrm{CHCl}_{3}\right) . \mathrm{IR}$ (film): 3467, 3294, 3071, 2959, 2928, 2885, 2121, $1719 \mathrm{~cm}^{-1} .{ }^{1} \mathrm{H}$ NMR $\left(\mathrm{CDCl}_{3}, 400 \mathrm{MHz}\right): \delta 8.11-8.03$ $(\mathrm{m}, 2 \mathrm{H}), 7.63-7.54(\mathrm{~m}, 1 \mathrm{H}), 7.50-7.41(\mathrm{~m}, 2 \mathrm{H}), 5.93(\mathrm{ddd}, J=17.1,10.4,6.0 \mathrm{~Hz}, 1 \mathrm{H}), 5.79(\mathrm{ddd}, J=$ 7.6, 6.5, 2.2 Hz, 1H), $5.30(\mathrm{dt}, J=17.1,1.2 \mathrm{~Hz}, 1 \mathrm{H}), 5.17(\mathrm{dt}, J=10.4,1.2 \mathrm{~Hz}, 1 \mathrm{H}), 4.53-4.42(\mathrm{~m}, 1 \mathrm{H})$, $2.56(\mathrm{~d}, J=2.2 \mathrm{~Hz}, 1 \mathrm{H}), 2.30-2.05(\mathrm{~m}, 2 \mathrm{H}) .{ }^{13} \mathrm{C} \mathrm{NMR}\left(\mathrm{CDCl}_{3}, 101 \mathrm{MHz}\right): \delta 165.4,140.0,133.4,129.9$, 129.8, 128.5, 115.5, 81.0, 74.7, 69.9, 62.2, 41.7. HRMS (ESI): $m / z$ calcd. for $\mathrm{C}_{14} \mathrm{H}_{14} \mathrm{NaO}_{3}{ }^{+}[\mathrm{M}+\mathrm{Na}]^{+}$ 253.0835; found 253.0837.

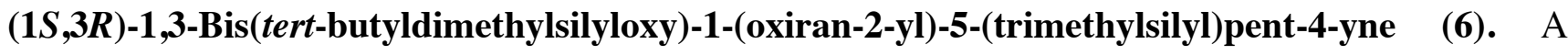
solution of $\mathbf{3 b}(0.900 \mathrm{~g}, 2.11 \mathrm{mmol})$ in anhydrous $\mathrm{CH}_{2} \mathrm{Cl}_{2}(5 \mathrm{~mL})$ was added to a suspension of $m$-CPBA $(77 \%, 1.417 \mathrm{~g}, 6.32 \mathrm{mmol})$ in anhydrous $\mathrm{CH}_{2} \mathrm{Cl}_{2}(10 \mathrm{~mL})$ at $\mathrm{rt}$ under $\mathrm{N}_{2}$ and the mixture was stirred at $\mathrm{rt}$ for $15 \mathrm{~h}$. The mixture was filtered and the organic phase was washed with saturated $\mathrm{Na}_{2} \mathrm{~S}_{2} \mathrm{O}_{3}(5 \mathrm{~mL})$, saturated $\mathrm{NaHCO}_{3}(10 \mathrm{~mL})$, dried $\left(\mathrm{MgSO}_{4}\right)$ and the solvent was removed to give the title compound (6) as a yellow oil $(0.853 \mathrm{~g}, 91 \%)$. IR (film): 3048, 2956, 2929, 2887, $2857 \mathrm{~cm}^{-1} .{ }^{1} \mathrm{H}$ NMR $\left(\mathrm{CDCl}_{3}, 400\right.$ $\mathrm{MHz}): \delta 4.61-4.54(\mathrm{~m}, 1 \mathrm{H}), 3.88(\mathrm{ddd}, J=6.5,6.4,4.2 \mathrm{~Hz}, 0.4 \mathrm{H}), 3.49(\mathrm{ddd}, J=8.7,7.0,4.5 \mathrm{~Hz}$, $0.6 \mathrm{H}), 3.00-2.92(\mathrm{~m}, 1 \mathrm{H}), 2.83-2.76(\mathrm{~m}, 0.6 \mathrm{H}), 2.70-2.64(\mathrm{~m}, 0.8 \mathrm{H}), 2.56(\mathrm{dd}, J=4.9,2.7 \mathrm{~Hz}, 0.6 \mathrm{H})$, 2.02-1.80 (m, 2H), 0.92-0.90 (m, 18H), 0.16-0.08 (m, 21H). ${ }^{13} \mathrm{C} \mathrm{NMR}\left(\mathrm{CDCl}_{3}, 101 \mathrm{MHz}\right): \delta 106.8$, $106.7,90.1,90.0,72.7,68.4,61.2,61.1,56.0,54.8,45.2,44.3,43.7,43.2,26.0,25.9,18.4,18.3,0.0,-$ 
$0.1,-4.2,-4.4,-4.5,-4.8,-4.9,-5.1 . \mathrm{HRMS}(\mathrm{ESI}): \mathrm{m} / \mathrm{z}$ calcd. for $\mathrm{C}_{22} \mathrm{H}_{47} \mathrm{O}_{3} \mathrm{Si}_{3}{ }^{+}[\mathrm{M}+\mathrm{H}]^{+} 443.2828$; found 443.2827 .

(1S,3R)-1,3-Bis(tert-butyldimethylsilyloxy)-1-(oxiran-2-yl)pent-4-yne (4b). A solution of 7b (2.260 $\mathrm{g}, 6.37 \mathrm{mmol})$ in anhydrous $\mathrm{CH}_{2} \mathrm{Cl}_{2}(5 \mathrm{~mL})$ was added to a suspension of $m$-CPBA $(77 \%, 3.180 \mathrm{~g}, 19.12$ mmol) in anhydrous $\mathrm{CH}_{2} \mathrm{Cl}_{2}(25 \mathrm{~mL})$ at $\mathrm{rt}$ under $\mathrm{N}_{2}$ and the mixture was stirred at $\mathrm{rt}$ for $15 \mathrm{~h}$. The mixture was filtered and the organic phase was washed with saturated $\mathrm{Na}_{2} \mathrm{~S}_{2} \mathrm{O}_{3}(10 \mathrm{~mL})$, saturated $\mathrm{NaHCO}_{3}(2 \times 10 \mathrm{~mL})$, dried $\left(\mathrm{MgSO}_{4}\right)$ and the solvent was removed to give an oily residue that was purified by flash chromatography [silica gel, hexanes-AcOEt, from 90:10 to 50:50 (gradient elution)] to give the title compound (4b) $)^{12}$ as a pale yellow oil $(2.240 \mathrm{~g}, 95 \%)$. IR (film): 3311, 3045, 2954, 2928, 2886, $2857 \mathrm{~cm}^{-1} .{ }^{1} \mathrm{H}$ NMR $\left(\mathrm{CDCl}_{3}, 300 \mathrm{MHz}\right): \delta 4.58(\mathrm{~m}, 1 \mathrm{H}), 3.83(\mathrm{dd}, J=7.8,4.7 \mathrm{~Hz}, 0.4 \mathrm{H}), 3.49$ $(\mathrm{ddd}, J=8.7,6.9,4.3 \mathrm{~Hz}, 0.6 \mathrm{H}), 2.97(\mathrm{ddd}, J=6.9,4.1,2.7 \mathrm{~Hz}, 0.6 \mathrm{H}), 2.93(\mathrm{ddd}, J=4.5,3.9,2.7 \mathrm{~Hz}$, $0.4 \mathrm{H}), 2.79(\mathrm{dd}, J=4.8,4.2 \mathrm{~Hz}, 0.6 \mathrm{H}), 2.72-2.64(\mathrm{~m}, 0.8 \mathrm{H}), 2.57(\mathrm{dd}, J=4.9,2.7 \mathrm{~Hz}, 0.6 \mathrm{H}), 2.43(\mathrm{~d}, J$ $=2.1 \mathrm{~Hz}, 0.4 \mathrm{H}), 2.41(\mathrm{~d}, J=2.1 \mathrm{~Hz}, 0.6 \mathrm{H}), 2.06-1.79(\mathrm{~m}, 2 \mathrm{H}), 0.92-0.88(\mathrm{~m}, 18 \mathrm{H}), 0.16-0.06(\mathrm{~m}, 12 \mathrm{H})$ ${ }^{13} \mathrm{C}$ NMR $\left(\mathrm{CDCl}_{3}, 101 \mathrm{MHz}\right): \delta 85.0,84.9,73.3,73.3,72.4,68.6,60.5,56.0,54.7,45.1,44.7,44.1$, $43.5,26.1,26.0,25.9,18.4,18.3,18.2,-4.2,-4.5,-4.9,-5.0,-5.1$. HRMS (ESI): $\mathrm{m} / z$ calcd. for $\mathrm{C}_{19} \mathrm{H}_{39} \mathrm{O}_{3} \mathrm{Si}_{2}^{+}[\mathrm{M}+\mathrm{H}]^{+}$371.2432; found 371.2425.

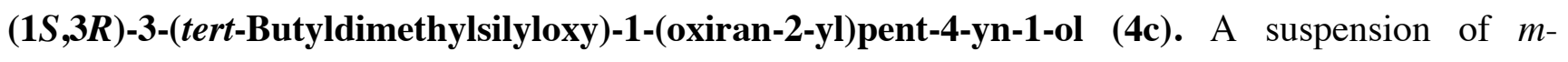
CPBA $(77 \%, 13.640 \mathrm{~g}, 60.83 \mathrm{mmol})$ in anhydrous $\mathrm{CH}_{2} \mathrm{Cl}_{2}(30 \mathrm{~mL})$ at $\mathrm{rt}$ under $\mathrm{N}_{2}$ was added to a stirred solution of 7c $(5.849 \mathrm{~g}, 24.33 \mathrm{mmol})$ in anhydrous $\mathrm{CH}_{2} \mathrm{Cl}_{2}(20 \mathrm{~mL})$ and the mixture was stirred at $\mathrm{rt}$ for 15 hours. The mixture was filtered and the organic phase was washed with saturated $\mathrm{Na}_{2} \mathrm{~S}_{2} \mathrm{O}_{3}(35 \mathrm{~mL})$, saturated $\mathrm{NaHCO}_{3}(2 \times 15 \mathrm{~mL})$, dried $\left(\mathrm{MgSO}_{4}\right)$ and the solvent was removed to give the title compound $(4 \mathrm{c})^{9 \mathrm{a}}$ as a yellow oil $(6.048 \mathrm{~g}, 97 \%)$. IR (film): 3454, 3318, 3083, 2962, 2930, 2895, $2860 \mathrm{~cm}^{-1} .{ }^{1} \mathrm{H}$ NMR $\left(\mathrm{CDCl}_{3}, 400 \mathrm{MHz}\right): \delta$ 4.58-4.54 (m, 1H), 3.89-3.83 (m, 0.4H), 3.72-3.65 (m, 0.6 H), 2.95 (ddd, J $=8.0,4.1,2.0 \mathrm{~Hz}, 1 \mathrm{H}), 2.71-2.63(\mathrm{~m}, 2 \mathrm{H}), 2.38(\mathrm{~d}, J=2.1 \mathrm{~Hz}, 0.4 \mathrm{H}), 2.47(\mathrm{~d}, J=2.1 \mathrm{~Hz}, 0.6 \mathrm{H}), 1.98-$ $1.81(\mathrm{~m}, 2 \mathrm{H}), 0.81(\mathrm{~s}, 9 \mathrm{H}), 0.08(\mathrm{~s}, 1.2 \mathrm{H}), 0.08(\mathrm{~s}, 1.8 \mathrm{H}), 0.06(\mathrm{~s}, 1.2 \mathrm{H}), 0.05(\mathrm{~s}, 1.8 \mathrm{H}) .{ }^{13} \mathrm{C} \mathrm{NMR}$ 
$\left(\mathrm{CDCl}_{3}, 101 \mathrm{MHz}\right): \delta 84.5,84.4,73.6,73.5,69.7,68.2,61.7,61.3,55.2,54.3,44.9,44.4,42.4,41.9$ 25.8, 18.2, 18.1, -4.3, -4.4, -5.0, -5.1. HRMS (ESI): $m / z$ calcd. for $\mathrm{C}_{13} \mathrm{H}_{25} \mathrm{O}_{3} \mathrm{Si}^{+}[\mathrm{M}+\mathrm{H}]^{+} 257.1568$; found 257.1559.

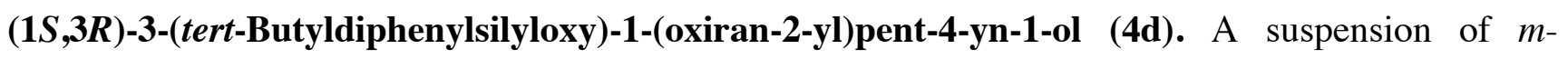
CPBA $(77 \%, 0.516 \mathrm{~g}, 2.26 \mathrm{mmol})$ in anhydrous $\mathrm{CH}_{2} \mathrm{Cl}_{2}(3 \mathrm{~mL})$ at $\mathrm{rt}$ under $\mathrm{N}_{2}$ was added to a stirred solution of $7 \mathbf{d}(0.275 \mathrm{~g}, 0.754 \mathrm{mmol})$ in anhydrous $\mathrm{CH}_{2} \mathrm{Cl}_{2}(2 \mathrm{~mL})$ and the mixture was stirred at $\mathrm{rt}$ for $2.5 \mathrm{~h}$. After filtration the organic phase was washed with saturated $\mathrm{Na}_{2} \mathrm{~S}_{2} \mathrm{O}_{3}(5 \mathrm{~mL})$, saturated $\mathrm{NaHCO}_{3}$ $(2 \times 15 \mathrm{~mL})$ and dried $\left(\mathrm{MgSO}_{4}\right)$. Solvent removal gave the title compound $(\mathbf{4 d})$ as a pale yellow oil (0.290 g, 99\%). IR (film): 3447, 3287, 2960, 2930, 2891, 2857, $2117 \mathrm{~cm}^{-1} .{ }^{1} \mathrm{H}$ NMR (CDCl, $\left.400 \mathrm{MHz}\right)$ : ठ 7.77-7.66 (m, 4H), 7.47-7.35 (m, 6H), 4.67-4.59 (m, 1H), 4.10-4.04 (m, 0.4H), 3.84-3.76 (s, 0.6H), $3.05(\mathrm{dd}, J=6.6,3.7 \mathrm{~Hz}, 0.4 \mathrm{H}), 2.98(\mathrm{td}, J=4.3,2.8 \mathrm{~Hz}, 0.6 \mathrm{H}), 2.79-2.68(\mathrm{~m}, 2 \mathrm{H}), 2.37(\mathrm{~d}, J=2.1 \mathrm{~Hz}$ 1H), 2.02-1.85 (m, 3H), $1.08(\mathrm{~s}, 9 \mathrm{H}) .{ }^{13} \mathrm{C} \mathrm{NMR}\left(\mathrm{CDCl}_{3}, 101 \mathrm{MHz}\right): \delta 136.2,136.1,135.9,133.2,133.2$, $133.2,130.10,130.1,130.0,127.9,127.8,127.6,127.5,84.1,84.1,74.3,74.2,68.8,66.7,61.9,61.7$ 55.2, 54.4, 45.0, 43.9, 42.7, 41.7, 27.0, 19.4. HRMS (ESI): $m / z$ calcd. for $\mathrm{C}_{23} \mathrm{H}_{28} \mathrm{NaO}_{3} \mathrm{Si}^{+}[\mathrm{M}+\mathrm{Na}]^{+}$ 403.1700; found 403.1702.

(1S,3R)-1-(Oxiran-2-yl)-3-(triisopropylsilyloxy)pent-4-yn-1-ol (4e). A solution of 7e (4.900 g, $17.34 \mathrm{mmol})$ in anhydrous $\mathrm{CH}_{2} \mathrm{Cl}_{2}(7 \mathrm{~mL})$ was added to a suspension of $m$-CPBA $(77 \%, 9.500 \mathrm{~g}, 42.48$ mmol) in anhydrous $\mathrm{CH}_{2} \mathrm{Cl}_{2}(33 \mathrm{~mL})$ at $\mathrm{rt}$ under $\mathrm{N}_{2}$ and the mixture was stirred at $\mathrm{rt}$ for $15 \mathrm{~h}$. After filtration the organic phase was washed with saturated $\mathrm{Na}_{2} \mathrm{~S}_{2} \mathrm{O}_{3}(20 \mathrm{~mL})$, saturated $\mathrm{NaHCO}_{3}(2 \times 20 \mathrm{~mL})$ and dried $\left(\mathrm{MgSO}_{4}\right)$. Solvent removal gave the title compound $(\mathbf{4 e})^{9 \mathrm{a}}$ as a pale yellow oil $(4.920 \mathrm{~g}, 95 \%)$. IR (film): 3447, 3310, 2944, 2867, $2109 \mathrm{~cm}^{-1} .{ }^{1} \mathrm{H}$ NMR $\left(\mathrm{CDCl}_{3}, 400 \mathrm{MHz}\right): \delta$ 4.80-4.74 (m, 1H), 4.09$4.02(\mathrm{~m}, 0.4 \mathrm{H}), 3.87-3.79(\mathrm{~m}, 0.6 \mathrm{H}), 3.11-3.04(\mathrm{~m}, 1 \mathrm{H}), 2.84-2.79(\mathrm{~m}, 1 \mathrm{H}), 2.78-2.74(\mathrm{~m}, 1 \mathrm{H}), 2.49(\mathrm{~d}$, $J=2.1 \mathrm{~Hz}, 0.4 \mathrm{H}), 2.47(\mathrm{~d}, J=2.1 \mathrm{~Hz}, 0.6 \mathrm{H}), 2.10-1.91(\mathrm{~m}, 2 \mathrm{H}), 1.13-1.04(\mathrm{~m}, 21 \mathrm{H}) .{ }^{13} \mathrm{C} \mathrm{NMR}\left(\mathrm{CDCl}_{3}\right.$, $101 \mathrm{MHz}): \delta 84.7,84.6,73.6,73.6,69.5,67.5,61.5,61.2,55.4,54.4,45.0,44.2,42.8,42.1,18.1,18.1$, 12.4, 12.3. HRMS (ESI): $m / z$ calcd. for $\mathrm{C}_{16} \mathrm{H}_{31} \mathrm{O}_{3} \mathrm{Si}^{+}[\mathrm{M}+\mathrm{H}]^{+}$299.2037; found 299.2035. 
(3R,5S)-5-Hydroxy-5-(oxiran-2-yl)pent-1-yn-3-yl benzoate (4f). A solution of $7 \mathbf{f}(0.500 \mathrm{~g}, 2.17$ mmol, 91:9 mixture of monobenzoylated regioisomers) in anhydrous $\mathrm{CH}_{2} \mathrm{Cl}_{2}(3 \mathrm{~mL})$ was added to a suspension of $m$-CPBA $(77 \%, 1.460 \mathrm{~g}, 6.51 \mathrm{mmol})$ in anhydrous $\mathrm{CH}_{2} \mathrm{Cl}_{2}(2 \mathrm{~mL})$ at $\mathrm{rt}$ under $\mathrm{N}_{2}$ and the mixture was stirred at $\mathrm{rt}$ for $15 \mathrm{~h}$. After filtration the organic phase was washed with saturated $\mathrm{Na}_{2} \mathrm{~S}_{2} \mathrm{O}_{3}$ $(7 \mathrm{~mL})$, saturated $\mathrm{NaHCO}_{3}(2 \times 10 \mathrm{~mL})$ and dried $\left(\mathrm{MgSO}_{4}\right)$. Solvent removal gave an oily residue that was purified by flash chromatography [silica gel, hexanes-AcOEt, from 90:10 to 50:50 (gradient elution)] to give the title compound (4f) as a pale yellow oil (0.465 $\mathrm{g}, 87 \%$, single monobenzoylated regioisomer). IR (film): 3446, 3288, 3063, 2997, 2929, 2121, $1719 \mathrm{~cm}^{-1} .{ }^{1} \mathrm{H} \mathrm{NMR}\left(\mathrm{CDCl}_{3}, 400 \mathrm{MHz}\right): \delta$ 8.07-8.01 (m, 2H), 7.60-7.53 (m, 1H), $7.44(\mathrm{t}, J=7.7 \mathrm{~Hz}, 2 \mathrm{H}), 5.89-5.81(\mathrm{~m}, 1 \mathrm{H}), 4.18(\mathrm{ddd}, J=7.9$, 4.8, 3.3 Hz, 0.4H), $3.86(\mathrm{dt}, J=9.0,4.6 \mathrm{~Hz}, 0.6 \mathrm{H}), 3.09(\mathrm{ddd}, J=7.4,6.0,2.9 \mathrm{~Hz}, 1 \mathrm{H}), 2.88-2.81(\mathrm{~m}$, $1 \mathrm{H}), 2.79-2.74(\mathrm{~m}, 0.6 \mathrm{H}), 2.72(\mathrm{dd}, J=5.0,4.0 \mathrm{~Hz}, 0.4 \mathrm{H}), 2.56(\mathrm{t}, J=1.9 \mathrm{~Hz}, 1 \mathrm{H}), 2.32-2.13(\mathrm{~m}, 2 \mathrm{H})$. ${ }^{13} \mathrm{C} \mathrm{NMR}\left(\mathrm{CDCl}_{3}, 101 \mathrm{MHz}\right): \delta 165.4,133.5,133.4,129.9,129.9,129.6,129.6,128.6,128.5,80.7$, 80.6, 74.9, 74.8, 68.5, 65.9, 62.1, 62.0, 55.1, 54.2, 45.1, 43.7, 39.3, 38.4. HRMS (ESI): $m / z$ calcd. for $\mathrm{C}_{14} \mathrm{H}_{15} \mathrm{O}_{4}^{+}[\mathrm{M}+\mathrm{H}]^{+}$247.0965; found 247.0966.

(1S,3R)-3-(tert-Butyldimethylsilyloxy)-1-(oxiran-2-yl)pent-4-ynyl acetate (4g). $\mathrm{NEt}_{3}(3.80 \mathrm{~mL}$, $27.89 \mathrm{mmol})$ was added dropwise to a solution of $\mathbf{4 c}(5.499 \mathrm{~g}, 21.45 \mathrm{mmol})$ and a catalytic amount of DMAP in anhydrous $\mathrm{CH}_{2} \mathrm{Cl}_{2}(50 \mathrm{~mL})$ at $0{ }^{\circ} \mathrm{C}$ under $\mathrm{N}_{2} . \mathrm{Ac}_{2} \mathrm{O}(2.40 \mathrm{~mL}, 25.74 \mathrm{mmol})$ was added dropwise at $0-5{ }^{\circ} \mathrm{C}$ and the mixture was allowed to warm to $\mathrm{rt}$ and stirred for $1 \mathrm{~h}$. Saturated $\mathrm{NH}_{4} \mathrm{Cl}(35$ $\mathrm{mL}$ ) was added slowly and the mixture was stirred for $10 \mathrm{~min}$. After partitioning the aqueous phase was extracted with $\mathrm{CH}_{2} \mathrm{Cl}_{2}(20 \mathrm{~mL})$ and the combined organic phases were washed with saturated $\mathrm{NaHCO}_{3}$ (30 mL). The aqueous phase was extracted with $\mathrm{CH}_{2} \mathrm{Cl}_{2}(20 \mathrm{~mL})$ and the combined organic phases were dried $\left(\mathrm{MgSO}_{4}\right)$ and the solvent was removed to give the title compound ${ }^{9 \mathrm{a}}(\mathbf{4 g})$ as a pale yellow oil (6.300 g, 98\%). IR (film): 3295, 3075, 2970, 2947, 2903, 2873, $1750 \mathrm{~cm}^{-1} .{ }^{1} \mathrm{H} \mathrm{NMR}\left(\mathrm{CDCl}_{3}, 400 \mathrm{MHz}\right): \delta$ 5.07-4.99 (m, 1H), 4.54-4.48 (m, 1H), 3.16 (ddd, $J=5.7,4.1,2.6 \mathrm{~Hz}, 0.6 \mathrm{H}), 3.05(\mathrm{ddd}, J=4.9,3.9,2.7$ $\mathrm{Hz}, 0.4 \mathrm{H}), 2.82(\mathrm{dd}, J=4.9,4.2 \mathrm{~Hz}, 0.6 \mathrm{H}), 2.77-2.70(\mathrm{~m}, 0.8 \mathrm{H}), 2.67(\mathrm{dd}, J=4.8,2.7 \mathrm{~Hz}, 0.6 \mathrm{H}), 2.44$ 
$(\mathrm{d}, J=2.1 \mathrm{~Hz}, 0.6 \mathrm{H}), 2.43(\mathrm{~d}, J=2.1 \mathrm{~Hz}, 0.4 \mathrm{H}), 2.08(\mathrm{~s}, 1.2 \mathrm{H}), 2.06(\mathrm{~s}, 1.8 \mathrm{H}), 2.16-1.97(\mathrm{~m}, 2 \mathrm{H}), 0.90$

$(\mathrm{s}, 9 \mathrm{H}), 0.15(\mathrm{~s}, 1.8 \mathrm{H}), 0.14(\mathrm{~s}, 1.2 \mathrm{H}), 0.12(\mathrm{~s}, 1.8 \mathrm{H}), 0.12(\mathrm{~s}, 1.2 \mathrm{H}) .{ }^{13} \mathrm{C} \mathrm{NMR}\left(\mathrm{CDCl}_{3}, 101 \mathrm{MHz}\right): \delta$ $171.1,85.1,74.5,74.4,72.0,70.9,60.8,54.1,53.2,46.3,40.9,40.7,26.8,22.1,22.0,19.2,-3.5,-4.1$. HRMS (ESI): $m / z$ calcd. for $\mathrm{C}_{15} \mathrm{H}_{27} \mathrm{O}_{4} \mathrm{Si}^{+}[\mathrm{M}+\mathrm{H}]^{+}$299.1674; found 299.1665.

\section{(5R,7S)-5-Ethynyl-2,2,3,3,10,10-hexamethyl-7-(oxiran-2-yl)-9,9-diphenyl-4,8-dioxa-3,9-}

disilaundecane (4h). TBDPSCl $(0.17 \mathrm{~mL}, 0.66 \mathrm{mmol})$ was added dropwise to a solution of $\mathbf{4 c}(0.085 \mathrm{~g}$, $0.33 \mathrm{mmol})$ and imidazole $(0.050 \mathrm{~g}, 0.73 \mathrm{mmol})$ in anhydrous $\mathrm{THF}(3 \mathrm{~mL})$ at $0{ }^{\circ} \mathrm{C}$ under $\mathrm{N}_{2}$, and the mixture was warmed to $30{ }^{\circ} \mathrm{C}$ and stirred for $48 \mathrm{~h}$. A $22 \%$ solution of $\mathrm{NH}_{4} \mathrm{Cl}(5 \mathrm{~mL})$ was added slowly and the mixture was stirred for $10 \mathrm{~min}$. MTBE $(15 \mathrm{~mL})$ and $\mathrm{H}_{2} \mathrm{O}(5 \mathrm{~mL})$ were added and the mixture was stirred for 10 min and partitioned. The organic phase was dried $\left(\mathrm{MgSO}_{4}\right)$, and the solvent was removed. The resulting oily residue was purified by flash chromatography (silica gel, hexanes-AcOEt 98:2) to give the title compound (4h) as a colorless oil (0.130 g, 79\%). IR (film): 3309, 3049, 2956, 2930, 2892, $2857 \mathrm{~cm}^{-1} .{ }^{1} \mathrm{H}$ NMR $\left(\mathrm{CDCl}_{3}, 400 \mathrm{MHz}\right): \delta$ 7.73-7.68 (m, 4H), 7.44-7.32 (m, 6H), 4.70 (ddd, $J=7.6,6.9,2.1 \mathrm{~Hz}, 0.4 \mathrm{H}), 4.57(\mathrm{dt}, J=6.8,2.1 \mathrm{~Hz}, 0.6 \mathrm{H}), 3.69-3.57(\mathrm{~m}, 1 \mathrm{H}), 3.11-3.04(\mathrm{~m}, 0.6 \mathrm{H})$, 2.90-2.84 (m, 0.4H), $2.67(\mathrm{dd}, J=4.8,4.3 \mathrm{~Hz}, 0.6 \mathrm{H}), 2.46(\mathrm{dd}, J=4.9,2.7 \mathrm{~Hz}, 0.6 \mathrm{H}), 2.32-2.28(\mathrm{~m}$, 0.6H), $2.20(\mathrm{~d}, J=2.1 \mathrm{~Hz}, 0.4 \mathrm{H}), 1.99(\mathrm{~m}, 1 \mathrm{H}), 1.91-1.82(\mathrm{~m}, 1 \mathrm{H}), 1.08(\mathrm{~s}, 9 \mathrm{H}), 0.85(\mathrm{~s}, 9 \mathrm{H}), 0.12(\mathrm{~s}$, 0.6H), 0.09 (s, 2.4H), $0.07(\mathrm{~s}, 0.6 \mathrm{H}), 0.07(\mathrm{~s}, 2.4 \mathrm{H}) .{ }^{13} \mathrm{C} \mathrm{NMR}\left(\mathrm{CDCl}_{3}, 101 \mathrm{MHz}\right): \delta 136.2,136.1,136.1$, $136.0,134.0,133.8,133.7,133.4,130.0,129.9,129.8,129.7,127.8,127.7,127.7,127.5,85.1,84.7$, $73.1,73.0,72.9,71.3,60.1,60.0,55.6,54.5,46.5,45.2,44.6,43.5,27.2,27.1,25.9,25.8,19.6,19.5$, 18.3, 18.2, -4.4, -4.5, -4.9. HRMS (ESI): $\mathrm{m} / \mathrm{z}$ calcd. for $\mathrm{C}_{29} \mathrm{H}_{46} \mathrm{NO}_{3} \mathrm{Si}_{2}{ }^{+}\left[\mathrm{M}+\mathrm{NH}_{4}\right]^{+}$512.3011; found 512.3005 .

(5R,7S)-5-Ethynyl-2,2,9,9,10,10-hexamethyl-7-(oxiran-2-yl)-3,3-diphenyl-4,8-dioxa-3,9-

disilaundecane (4i). A solution of $\mathrm{TBSCl}(0.230 \mathrm{~g}, 1.53 \mathrm{mmol})$ in anhydrous $\mathrm{THF}(2 \mathrm{~mL})$ was added dropwise to a solution of $\mathbf{4 d}(0.220 \mathrm{~g}, 0.58 \mathrm{mmol})$ and imidazole $(0.110 \mathrm{~g}, 1.62 \mathrm{mmol})$ in anhydrous THF (3 mL) at $0{ }^{\circ} \mathrm{C}$ under $\mathrm{N}_{2}$, and the mixture was warmed to $30{ }^{\circ} \mathrm{C}$ and stirred for $24 \mathrm{~h}$. A $22 \%$ 
solution of $\mathrm{NH}_{4} \mathrm{Cl}(5 \mathrm{~mL})$ was added slowly and the mixture was stirred for $10 \mathrm{~min}$. MTBE (15 mL) and $\mathrm{H}_{2} \mathrm{O}(5 \mathrm{~mL})$ were added and the mixture was stirred for $10 \mathrm{~min}$ and partitioned. The organic phase was dried $\left(\mathrm{MgSO}_{4}\right)$, and the solvent was removed. The resulting oily residue was purified by flash chromatography [silica gel, hexanes-AcOEt, from 99:1 to 90:10 (gradient elution)] to give the title compound (4i) as a colorless oil $(0.203 \mathrm{~g}, 71 \%)$. IR (film): 3307, 3071, 2955, 2928, 2892, $2856 \mathrm{~cm}^{-1} \cdot{ }^{1} \mathrm{H}$ NMR $\left(\mathrm{CDCl}_{3}, 300 \mathrm{MHz}\right): \delta$ 7.89-7.78 $(\mathrm{m}, 4 \mathrm{H}), 7.60-7.46(\mathrm{~m}, 6 \mathrm{H}), 4.71-4.62(\mathrm{~m}, 1 \mathrm{H}), 3.93(\mathrm{dt}, J=8.0$, $4.1 \mathrm{~Hz}, 0.3 \mathrm{H}), 3.64-3.54(\mathrm{~m}, 0.7 \mathrm{H}), 3.07-2.96(\mathrm{~m}, 1 \mathrm{H}), 2.88(\mathrm{dd}, J=4.8,4.2 \mathrm{~Hz}, 0.7 \mathrm{H}), 2.80(\mathrm{dd}, J=$ 5.4, 4.2 Hz, 0.3H), $2.74(\mathrm{dd}, J=5.4,2.8 \mathrm{~Hz}, 0.3 \mathrm{H}), 2.66(\mathrm{dd}, J=4.9,2.8 \mathrm{~Hz}, 0.7 \mathrm{H}), 2.50(\mathrm{~d}, J=2.1$ $\mathrm{Hz}, 0.3 \mathrm{H}), 2.48(\mathrm{~d}, J=2.1 \mathrm{~Hz}, 0.7 \mathrm{H}), 2.20-2.00(\mathrm{~m}, 2 \mathrm{H}), 1.22(\mathrm{bs}, 9 \mathrm{H}), 0.87(\mathrm{bs}, 6 \mathrm{H}), 0.84(\mathrm{~s}, 3 \mathrm{H}), 0.19$ $(\mathrm{s}, 2 \mathrm{H}), 0.14(\mathrm{~s}, 1 \mathrm{H}), 0.11(\mathrm{~s}, 1 \mathrm{H}), 0.04(\mathrm{~s}, 2 \mathrm{H}) .{ }^{13} \mathrm{C} \mathrm{NMR}\left(\mathrm{CDCl}_{3}, 101 \mathrm{MHz}\right): \delta 136.2,136.1,135.9$ $135.9,133.5,133.4,130.0,129.9,129.8,129.7,127.8,127.8,127.6,127.5,84.5,84.4,74.1,74.0,72.4$ $68.6,61.8,56.0,54.7,45.0,44.7,43.6,43.0,27.0,25.9,25.9,19.4,18.1,18.1,-4.4,-4.3,-5.1,-5.3$. HRMS (ESI): $m / z$ calcd. for $\mathrm{C}_{29} \mathrm{H}_{42} \mathrm{NaO}_{3} \mathrm{Si}_{2}{ }^{+}[\mathrm{M}+\mathrm{Na}]^{+}$517.2565; found 517.2572.

(1S,3R)-1-(Oxiran-2-yl)-3-(triisopropylsilyloxy)pent-4-yn-1-yl acetate (4j). $\mathrm{NEt}_{3}(0.29 \mathrm{~mL}, 2.15$ mmol) was added dropwise to a solution of $4 \mathbf{e}(0.495 \mathrm{~g}, 1.66 \mathrm{mmol})$ and a catalytic amount of DMAP in anhydrous $\mathrm{CH}_{2} \mathrm{Cl}_{2}(5 \mathrm{~mL})$ at $0{ }^{\circ} \mathrm{C}$ under $\mathrm{N}_{2} . \mathrm{Ac}_{2} \mathrm{O}(0.19 \mathrm{~mL}, 1.99 \mathrm{mmol})$ was added dropwise at $0{ }^{\circ} \mathrm{C}$ and the mixture was allowed to warm to $\mathrm{rt}$ and stirred for $1 \mathrm{~h}$. Saturated $\mathrm{NH}_{4} \mathrm{Cl}(5 \mathrm{~mL})$ was added slowly and the mixture was stirred for $10 \mathrm{~min}$. After partitioning the aqueous phase was extracted with $\mathrm{CH}_{2} \mathrm{Cl}_{2}(5 \mathrm{~mL})$ and the organic phases were combined and washed with saturated $\mathrm{NaHCO}_{3}(2 \times 5 \mathrm{~mL})$. The combined organic phases were dried $\left(\mathrm{MgSO}_{4}\right)$, and solvent removal gave the title compound $(\mathbf{4} \mathbf{j})$ as a yellow oil $(0.508 \mathrm{~g}, 90 \%)$. IR (film): 3301, 3064, 2944, 2867, $2118 \mathrm{~cm}^{-1} .{ }^{1} \mathrm{H}$ NMR $\left(\mathrm{CDCl}_{3}, 400 \mathrm{MHz}\right)$ : ઈ 5.12-5.06 (m, 1H), 4.64-4.55 (m, 1H), 3.17 (ddd, $J=5.6,4.2,2.7 \mathrm{~Hz}, 0.6 \mathrm{H}), 3.07(\mathrm{ddd}, J=4.4,3.7$, $2.6 \mathrm{~Hz}, 0.4 \mathrm{H}), 2.83(\mathrm{dd}, J=4.9,4.2 \mathrm{~Hz}, 0.6 \mathrm{H}), 2.75(\mathrm{~m}, 0.8 \mathrm{H}), 2.68(\mathrm{dd}, J=4.9,2.6 \mathrm{~Hz}, 0.6 \mathrm{H}), 2.44$ $(\mathrm{m}, 1 \mathrm{H}), 2.15-1.99(\mathrm{~m}, 5 \mathrm{H}), 1.18-0.98(\mathrm{~m}, 21 \mathrm{H}) .{ }^{13} \mathrm{C} \mathrm{NMR}\left(\mathrm{CDCl}_{3}, 101 \mathrm{MHz}\right): \delta 170.1,84.1,73.5,73.4$ $70.9,69.8,60.0,59.9,53.2,52.2,45.3,40.2,39.7,21.0,20.9,18.1,18.0,17.8,12.4,12.3,12.2$. HRMS 
(ESI): $m / z$ calcd. for $\mathrm{C}_{18} \mathrm{H}_{33} \mathrm{O}_{4} \mathrm{Si}^{+}[\mathrm{M}+\mathrm{H}]^{+}$341.2143; found 341.2141.

$(3 R, 5 S)-5-(t e r t-B u t y l d i m e t h y l s i l y l o x y)-5-(0 x i r a n-2-y l) p e n t-1-y n-3-y l$ benzoate (4k). A solution of TBSCl $(0.464 \mathrm{~g}, 3.08 \mathrm{mmol})$ in anhydrous THF $(2 \mathrm{~mL})$ was added dropwise to a solution of $\mathbf{4 f}(0.400 \mathrm{~g}$, $1.62 \mathrm{mmol})$ and imidazole $(0.330 \mathrm{~g}, 4.86 \mathrm{mmol})$ in anhydrous $\mathrm{THF}(3 \mathrm{~mL})$ at $0{ }^{\circ} \mathrm{C}$ under $\mathrm{N}_{2}$, and the mixture was warmed to $30{ }^{\circ} \mathrm{C}$ and stirred for $24 \mathrm{~h}$. A $22 \%$ solution of $\mathrm{NH}_{4} \mathrm{Cl}(5 \mathrm{~mL})$ was added slowly and the mixture was stirred for $10 \mathrm{~min}$. MTBE $(15 \mathrm{~mL})$ and $\mathrm{H}_{2} \mathrm{O}(5 \mathrm{~mL})$ were added and the mixture was stirred for $10 \mathrm{~min}$ and partitioned. The organic phase was dried $\left(\mathrm{MgSO}_{4}\right)$, and the solvent was removed. The resulting oily residue was purified by flash chromatography [silica gel, hexanes-AcOEt, from 95:5 to 90:10 (gradient elution)] to give the title compound (4k) as a white waxy solid (0.390 $\mathrm{g}$, 67\%). IR (film): 3270, 3066, 2954, 2928, 2886, 2856, 2121, $1724 \mathrm{~cm}^{-1} .{ }^{1} \mathrm{H} \mathrm{NMR}\left(\mathrm{CDCl}_{3}, 300 \mathrm{MHz}\right): \delta$ 8.09-8.03 (m, 2H), 7.62-7.53 (m, 1H), 7.48-7.41 (m, 2H), 5.83-5.75 (m, 1H), $3.90(\mathrm{dt}, J=7.4,4.6 \mathrm{~Hz}$ 0.3H), $3.60(\mathrm{ddd}, J=8.7,6.8,4.4 \mathrm{~Hz}, 0.7 \mathrm{H}), 3.02-2.80(\mathrm{~m}, 1 \mathrm{H}), 2.70-2.66(\mathrm{~m}, 0.6 \mathrm{H}), 2.53(\mathrm{~m}, 1.4 \mathrm{H})$, 2.29-2.18 (m, 1H), 2.14-2.03 (m, 1H), $0.93(\mathrm{bs}, 9 \mathrm{H}), 0.16(\mathrm{~s}, 1.5 \mathrm{H}), 0.14(\mathrm{~s}, 3 \mathrm{H}), 0.09(\mathrm{~s}, 1.5 \mathrm{H}) .{ }^{13} \mathrm{C}$ NMR $\left(\mathrm{CDCl}_{3}, 101 \mathrm{MHz}\right): \delta 165.3,165.2,133.4,133.4,129.9,129.8,129.7,128.6,128.5,80.8,74.8$ $74.7,72.0,68.6,62.1,61.8,55.7,54.5,45.2,45.0,40.1,39.6,26.0,25.9,18.2,-4.2,-4.3,-4.9,-5.1$. HRMS (ESI): $m / z$ calcd. for $\mathrm{C}_{20} \mathrm{H}_{32} \mathrm{NO}_{4} \mathrm{Si}^{+}\left[\mathrm{M}+\mathrm{NH}_{4}\right]^{+}$378.2095; found 378.2099.

\section{General procedure for non-catalytic 5-exo cyclization}

Strictly deoxygenated anhydrous THF $(76 \mathrm{~mL})$ was added to a mixture of $\mathrm{Cp}_{2} \mathrm{TiCl}_{2}(1.711 \mathrm{~g}, 6.87$ mmol) and activated $\mathrm{Zn}$ powder $(1.800 \mathrm{~g}, 27.48 \mathrm{mmol})$ under $\mathrm{N}_{2}$ and the suspension was stirred at $\mathrm{rt}$ until it turned lime green. This suspension was then added slowly to a solution of $\mathbf{4 b}(0.850 \mathrm{~g}, 2.29$ mmol) over $3 \mathrm{~h}$ and the mixture was stirred for $15 \mathrm{~h}$ at $\mathrm{rt}$. A $22 \%$ solution of $\mathrm{NH}_{4} \mathrm{Cl}(60 \mathrm{~mL})$ was added slowly and the mixture was stirred for $2 \mathrm{~h}$, filtered and the solvent was removed. AcOEt (100 mL) was added and the mixture was stirred for $10 \mathrm{~min}$. The mixture was partitioned and the aqueous phase was extracted with AcOEt $(2 \times 50 \mathrm{~mL})$. The combined organic phases were dried $\left(\mathrm{MgSO}_{4}\right)$ and the solvent was removed. The resulting oily residue was purified by flash chromatography [silica gel, hexanes- 
AcOEt, from 95:5 to 80:20 (gradient elution)] to give the title compound as a pale yellow oil (0.424 $\mathrm{g}$, $50 \%)$

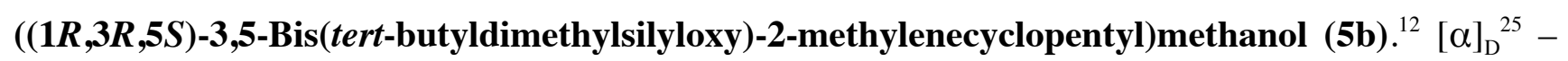
30.4 (c 1.0, $\left.\mathrm{CHCl}_{3}\right)$. IR (film): 3460, 3070, 2956, 2930, 2887, $2858 \mathrm{~cm}^{-1} .{ }^{1} \mathrm{H} \mathrm{NMR}\left(\mathrm{CDCl}_{3}, 400 \mathrm{MHz}\right): \delta$ $5.21(\mathrm{t}, J=2.3 \mathrm{~Hz}, 1 \mathrm{H}), 5.01(\mathrm{t}, J=2.3 \mathrm{~Hz}, 1 \mathrm{H}), 4.33(\mathrm{ddd}, J=9.3,4.8,2.3 \mathrm{~Hz}, 1 \mathrm{H}), 4.00(\mathrm{ddd}, J=$ $10.1,8.0,6.2 \mathrm{~Hz}, 1 \mathrm{H}), 3.82-3.69(\mathrm{~m}, 2 \mathrm{H}), 2.66-2.59(\mathrm{~m}, 1 \mathrm{H}), 2.24(\mathrm{dd}, J=11.6,6.2 \mathrm{~Hz}, 1 \mathrm{H}), 1.67-1.61$ $(\mathrm{m}, 1 \mathrm{H}), 0.92(\mathrm{~s}, 9 \mathrm{H}), 0.89(\mathrm{~s}, 9 \mathrm{H}), 0.10(\mathrm{~s}, 3 \mathrm{H}), 0.09(\mathrm{~s}, 6 \mathrm{H}), 0.08(\mathrm{~s}, 3 \mathrm{H}) .{ }^{13} \mathrm{C} \mathrm{NMR}\left(\mathrm{CDCl}_{3}, 101\right.$ MHz): $\delta 152.1,108.4,72.4,71.0,63.0,53.2,43.9,26.0,25.9,18.4,18.1,-4.1,-4.4,-4.6,-4.7 . \mathrm{HRMS}$ (ESI): $m / z$ calcd. for $\mathrm{C}_{19} \mathrm{H}_{41} \mathrm{O}_{3} \mathrm{Si}_{2}{ }^{+}[\mathrm{M}+\mathrm{H}]^{+} 373.2589$; found 373.2592.

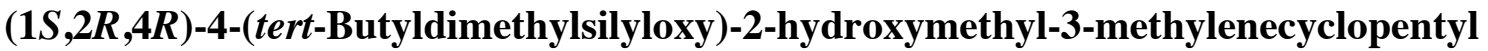

acetate

$(5 \mathrm{~g}) .^{9 \mathrm{a}}[\alpha]_{\mathrm{D}}{ }^{25}-43.5\left(c 1.0, \mathrm{CHCl}_{3}\right)$. IR (film): 3462, 3083, 2955, 2930, 2887, 2858, $1734 \mathrm{~cm}^{-1} .{ }^{1} \mathrm{H}$ NMR $\left(\mathrm{CDCl}_{3}, 400 \mathrm{MHz}\right): \delta 5.24(\mathrm{t}, J=2.3 \mathrm{~Hz}, 1 \mathrm{H}), 5.1(\mathrm{t}, J=2.3 \mathrm{~Hz}, 1 \mathrm{H}), 4.99(\mathrm{dt}, J=8.4,6.4 \mathrm{~Hz}, 1 \mathrm{H})$, $4.42(\mathrm{~m}, 1 \mathrm{H}), 3.70(\mathrm{~d}, J=5.8 \mathrm{~Hz}, 2 \mathrm{H}), 2.84-2.73(\mathrm{~m}, 1 \mathrm{H}), 2.48-2.38(\mathrm{~m}, 1 \mathrm{H}), 2.07(\mathrm{~s}, 3 \mathrm{H}), 1.81-1.69$ $(\mathrm{m}, 1 \mathrm{H}), 0.91(\mathrm{~s}, 9 \mathrm{H}), 0.10(\mathrm{~s}, 3 \mathrm{H}), 0.09(\mathrm{~s}, 3 \mathrm{H}) .{ }^{13} \mathrm{C} \mathrm{NMR}\left(\mathrm{CDCl}_{3}, 101 \mathrm{MHz}\right): \delta 171.9,151.7,109.0$ 73.5, 72.7, 63.7, 51.0, 40.5, 25.9, 21.3, 18.3, -4.5, -4.7. HRMS (ESI): $\mathrm{m} / z$ calcd. for $\mathrm{C}_{15} \mathrm{H}_{29} \mathrm{O}_{4} \mathrm{Si}^{+}$ $[\mathrm{M}+\mathrm{H}]^{+}$301.1830; found 301.1816.

\section{$((1 R, 3 R, 5 S)-3-($ tert-Butyldimethylsilyloxy)-5-(tert-butyldiphenylsilyloxy)-2-}

methylenecyclopentyl)methanol (5h). $[\alpha]_{\mathrm{D}}{ }^{25}-18.3\left(c 1.0, \mathrm{CHCl}_{3}\right)$. IR (ATR): 3454, 3070, 2955, 2929, 2888, $2856 \mathrm{~cm}^{-1} .{ }^{1} \mathrm{H}$ NMR $\left(\mathrm{CDCl}_{3}, 400 \mathrm{MHz}\right): \delta$ 7.73-7.65 (m, 4H), 7.47-7.35 (m, 6H), $5.17(\mathrm{t}, J=2.3$ $\mathrm{Hz}, 1 \mathrm{H}), 4.99(\mathrm{t}, J=2.3 \mathrm{~Hz}, 1 \mathrm{H}), 4.18-4.09(\mathrm{~m}, 1 \mathrm{H}), 4.02(\mathrm{dt}, J=9.5,6.7 \mathrm{~Hz}, 1 \mathrm{H}), 3.60(\mathrm{dd}, J=11.1$, $4.8 \mathrm{~Hz}, 1 \mathrm{H}), 3.49(\mathrm{dd}, J=11.1,4.5 \mathrm{~Hz}, 1 \mathrm{H}), 2.75-2.71(\mathrm{~m}, 1 \mathrm{H}), 2.01-1.92(\mathrm{~m}, 1 \mathrm{H}), 1.63(\mathrm{dt}, J=11.4$, $9.5 \mathrm{~Hz}, 1 \mathrm{H}), 1.06(\mathrm{~s}, 9 \mathrm{H}), 0.86(\mathrm{~s}, 9 \mathrm{H}), 0.00(\mathrm{~s}, 3 \mathrm{H}),-0.02(\mathrm{~s}, 3 \mathrm{H}) .{ }^{13} \mathrm{C} \mathrm{NMR}\left(\mathrm{CDCl}_{3}, 101 \mathrm{MHz}\right): \delta$ $152.4,136.0,134.3,134.0,131.0,130.0,129.9,128.0,127.9,127.8,126.7,108.2,72.4,71.6,62.7,53.6$, 43.7, 27.1, 26.0, 19.3, 18.3, -4.5, -4.7. HRMS (ESI): $m / z$ calcd. for $\mathrm{C}_{29} \mathrm{H}_{48} \mathrm{NO}_{3} \mathrm{Si}_{2}^{+}\left[\mathrm{M}+\mathrm{NH}_{4}\right]^{+}$514.3167; found 514.3165 . 
(5k). $[\alpha]_{\mathrm{D}}{ }^{25}-26.4\left(c 1.0, \mathrm{CHCl}_{3}\right)$. IR (ATR): 3503, 3064, 2954, 2929, 2885, 2856, $1718 \mathrm{~cm}^{-1} .{ }^{1} \mathrm{H}$ NMR $\left(\mathrm{CDCl}_{3}, 400 \mathrm{MHz}\right): \delta 8.10-8.04(\mathrm{~m}, 2 \mathrm{H}), 7.61-7.53(\mathrm{~m}, 1 \mathrm{H}), 7.49-7.40(\mathrm{~m}, 2 \mathrm{H})$, 5.66-5.61 (m, 1H), 5.37 $(\mathrm{t}, J=2.4 \mathrm{~Hz}, 1 \mathrm{H}), 5.19(\mathrm{t}, J=2.4 \mathrm{~Hz}, 1 \mathrm{H}), 4.19-4.10(\mathrm{~m}, 1 \mathrm{H}), 3.86-3.80(\mathrm{~m}, 2 \mathrm{H}), 2.81-2.71(\mathrm{~m}, 1 \mathrm{H})$, 2.64-2.55 (m, 1H), $1.83(\mathrm{dt}, J=12.7,8.4 \mathrm{~Hz}, 1 \mathrm{H}), 0.90(\mathrm{~s}, 9 \mathrm{H}), 0.11(\mathrm{~s}, 3 \mathrm{H}), 0.09(\mathrm{~s}, 3 \mathrm{H}) .{ }^{13} \mathrm{C} \mathrm{NMR}$ $\left(\mathrm{CDCl}_{3}, 101 \mathrm{MHz}\right): \delta 166.5,147.7,133.1,130.3,129.8,128.5,112.0,74.2,72.2,62.5,53.5,40.5,25.9$, 18.0, -4.3, -4.8. HRMS (ESI): $m / z$ calcd. for $\mathrm{C}_{20} \mathrm{H}_{31} \mathrm{O}_{4} \mathrm{Si}^{+}[\mathrm{M}+\mathrm{H}]^{+}$363.1986; found 363.1988.

\section{Catalytic 5-exo cyclization of $\mathbf{4 g}$}

Strictly deoxygenated anhydrous THF $(15 \mathrm{~mL})$ was added to a mixture of $\operatorname{IrCl}(\mathrm{CO})\left(\mathrm{PPh}_{3}\right)_{2}(0.260 \mathrm{~g}$, $0.34 \mathrm{mmol})$ and manganese powder $(0.368 \mathrm{~g}, 6.70 \mathrm{mmol})$. A solution of 2,4,6-collidine $(3.5 \mathrm{~mL}, 26.8$ mmol) and 4g (1.000 g, $3.35 \mathrm{mmol})$ in strictly deoxygenated anhydrous THF (22 mL) was added at rt. TMSCl $(1.7 \mathrm{~mL}, 13.4 \mathrm{mmol})$ was added followed by a solution of $\mathrm{Cp}_{2} \mathrm{TiCl}_{2}(0.167 \mathrm{~g}, 0.67 \mathrm{mmol})$ in strictly deoxygenated anhydrous THF $(12 \mathrm{~mL})$ and the mixture was stirred for $4 \mathrm{~h}$ under $\mathrm{H}_{2}(4 \mathrm{bar})$ at $\mathrm{rt}$. Water $(5 \mathrm{~mL})$ was added and the mixture was stirred for $10 \mathrm{~min}$ and filtered through Celite®. The pad was washed with MTBE $(20 \mathrm{~mL})$ and the organic phases were combined and acidified to $\mathrm{pH}=2$ with 2 $\mathrm{M} \mathrm{HCl}$. The mixture was stirred for $15 \mathrm{~min}$ and the phases were separated. The organic phase was washed with $\mathrm{H}_{2} \mathrm{O}(20 \mathrm{~mL})$ and dried $\left(\mathrm{Na}_{2} \mathrm{SO}_{4}\right)$. The solvent was removed and the resulting oily residue was purified by flash chromatography [silica gel, hexanes-AcOEt, from 90:10 to 60:40 (gradient elution)] to give the title compound $(\mathbf{5 g})$ as a pale yellow oil $(0.582 \mathrm{~g}, 58 \%)$.

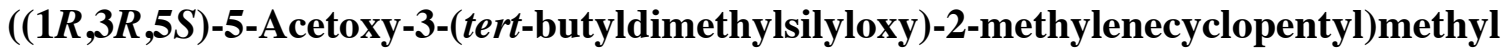

nitrobenzoate $\mathbf{( 5 l}) . \mathrm{NEt}_{3}(0.65 \mathrm{ml}, 4.62 \mathrm{~mol})$ was added dropwise to a solution of $\mathbf{5 g}(1.000 \mathrm{~g}, 3.33$ mmol) and a catalytic amount of DMAP in anhydrous $\mathrm{CH}_{2} \mathrm{Cl}_{2}(9 \mathrm{~mL})$ at $0{ }^{\circ} \mathrm{C}$ under $\mathrm{N}_{2}$. A solution of p-nitrobenzoyl chloride $(0.740 \mathrm{~g}, 3.99 \mathrm{mmol})$ in anhydrous $\mathrm{CH}_{2} \mathrm{Cl}_{2}(4 \mathrm{~mL})$ was added dropwise at $0-5$ ${ }^{\circ} \mathrm{C}$. The mixture was allowed to warm to $\mathrm{rt}$ and was stirred for $2 \mathrm{~h}$. Saturated $\mathrm{NH}_{4} \mathrm{Cl}(10 \mathrm{~mL})$ was added slowly and the mixture was stirred for $15 \mathrm{~min}$. The mixture was partitioned and the organic phase was 
washed with $\mathrm{H}_{2} \mathrm{O}$ and dried $\left(\mathrm{Na}_{2} \mathrm{SO}_{4}\right)$. The solvent was removed and the resulting oily residue was purified by flash chromatography (silica gel, hexanes-AcOEt 90:10) to give the title compound (5l) as white solid (1.102 g, 74\% yield). $\mathrm{Mp} 83{ }^{\circ} \mathrm{C} .[\alpha]_{\mathrm{D}}{ }^{25}-8.6\left(c 1.0, \mathrm{CHCl}_{3}\right)$. IR (ATR): 2981, 2959, 2944, 2884, 2858, 1730, $1713 \mathrm{~cm}^{-1} .{ }^{1} \mathrm{H} \mathrm{NMR}\left(\mathrm{CDCl}_{3}, 400 \mathrm{MHz}\right): \delta 8.31-8.13(\mathrm{~m}, 4 \mathrm{H}), 5.27(\mathrm{t}, J=2.3 \mathrm{~Hz}$, $1 \mathrm{H}), 5.13(\mathrm{t}, J=2.3 \mathrm{~Hz}, 1 \mathrm{H}), 5.05(\mathrm{dt}, J=8.4,6.6 \mathrm{~Hz}, 1 \mathrm{H}), 4.48(\mathrm{~m}, 3 \mathrm{H}), 3.18-3.08(\mathrm{~m}, 1 \mathrm{H}), 2.59-2.44$ $(\mathrm{m}, 1 \mathrm{H}), 1.99(\mathrm{~s}, 3 \mathrm{H}), 1.79-1.64(\mathrm{~m}, 1 \mathrm{H}), 0.91(\mathrm{~s}, 9 \mathrm{H}), 0.10(\mathrm{~s}, 3 \mathrm{H}), 0.09(\mathrm{~s}, 3 \mathrm{H}) .{ }^{13} \mathrm{C} \mathrm{NMR}\left(\mathrm{CDCl}_{3}, 101\right.$ MHz): $\delta 170.9,164.6,150.7,150.5,135.5,130.8,123.7,110.1,73.2,72.5,66.3,46.9,40.5,25.9,21.2$, 18.3, -4.5, -4.6. HRMS (ESI): $m / z$ calcd. for $\mathrm{C}_{22} \mathrm{H}_{32} \mathrm{NO}_{7} \mathrm{Si}^{+}[\mathrm{M}+\mathrm{H}]^{+} 450.1943$; found 450.1947.

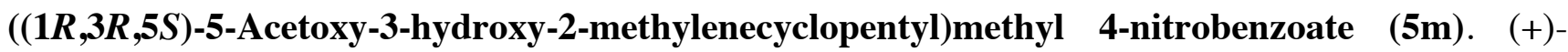
Camphorsulfonic acid ((+)-CSA, $0.034 \mathrm{~g}, 0.15 \mathrm{mmol})$ was added to a solution of $\mathbf{5 l}(0.660 \mathrm{~g}, 1.47$ mmol) in anhydrous $\mathrm{MeOH}(7 \mathrm{~mL})$ at $\mathrm{rt}$ under $\mathrm{N}_{2}$. The mixture was stirred for $2 \mathrm{~h}$ and was then cooled to $0{ }^{\circ} \mathrm{C}$ and stirred for $1 \mathrm{~h}$. The $\mathrm{pH}$ was adjusted to 6.5 by adding $1 \% \mathrm{NaHCO}_{3}$ solution. The $\mathrm{MeOH}$ was removed in vacuo and the aqueous layer was extracted with MTBE. The organic phase was dried $\left(\mathrm{Na}_{2} \mathrm{SO}_{4}\right)$, the solvent was removed and the resulting oily residue was purified by flash chromatography ( silica gel, hexanes-AcOEt 60:40) to give the title compound (5m) as a white solid (0.439 g, 89\%). Mp $73{ }^{\circ} \mathrm{C} .[\alpha]_{\mathrm{D}}^{25}-32.7\left(c 1.0, \mathrm{CHCl}_{3}\right) . \mathrm{IR}(\mathrm{KBr}): 3460,3109,3074,3050,2990,2927,1722 \mathrm{~cm}^{-1} .{ }^{1} \mathrm{H}$ NMR $\left(\mathrm{CDCl}_{3}, 400 \mathrm{MHz}\right): \delta 8.26-8.22(\mathrm{~m}, 4 \mathrm{H}), 5.44(\mathrm{bs}, 1 \mathrm{H}), 5.25(\mathrm{~d}, J=1.5 \mathrm{~Hz}, 1 \mathrm{H}), 5.17(\mathrm{q}, J=5.5 \mathrm{~Hz}$, $1 \mathrm{H}), 4.56-4.54(\mathrm{~m}, 1 \mathrm{H}), 4.52-4.43(\mathrm{~m}, 1 \mathrm{H}), 4.42-4.30(\mathrm{~m}, 1 \mathrm{H}), 3.21-3.18(\mathrm{~m}, 1 \mathrm{H}), 2.53-2.49(\mathrm{~m}, 1 \mathrm{H})$, $2.02(\mathrm{~s}, 3 \mathrm{H}), 1.85(\mathrm{dt}, J=12.4,5.5 \mathrm{~Hz}, 1 \mathrm{H}) .{ }^{13} \mathrm{C} \mathrm{NMR}\left(\mathrm{CDCl}_{3}, 101 \mathrm{MHz}\right): \delta 170.6,164.6,151.3,150.8$, 135.4, 130.8, 123.8, 112.3, 74.8, 73.2, 65.9, 47.9, 40.1, 21.3. HRMS (ESI): $m / z$ calcd. for $\mathrm{C}_{16} \mathrm{H}_{21} \mathrm{~N}_{2} \mathrm{O}_{7}^{+}$ $\left[\mathrm{M}+\mathrm{NH}_{4}\right]^{+}$353.1343; found 353.1328.

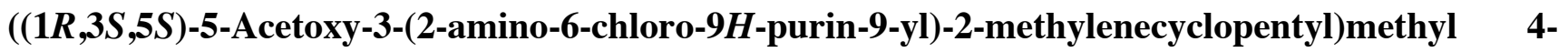
nitrobenzoate (13). A mixture of 2-amino-6-chloropurine $(7.380 \mathrm{~g}, 43.54 \mathrm{mmol})$ and triphenylphosphine $(11.400 \mathrm{~g}, 43.54 \mathrm{mmol})$ in anhydrous $\mathrm{THF}(927 \mathrm{~mL})$ at $\mathrm{rt}$ under $\mathrm{N}_{2}$ was stirred for $15 \mathrm{~min}$. After cooling to $-10{ }^{\circ} \mathrm{C}$, diisopropyl azodicarboxylate (DIAD, $8.60 \mathrm{~mL}, 43.54 \mathrm{mmol}$ ) was added 
dropwise and the mixture was stirred for $10 \mathrm{~min}$. A solution of $\mathbf{5 m}(7.300 \mathrm{~g}, 21.77 \mathrm{mmol})$ in anhydrous THF (160 mL) was added over $1 \mathrm{~h}$. The mixture was stirred for $3 \mathrm{~h}$ at $-10{ }^{\circ} \mathrm{C}$ and was then allowed to warm to rt, filtered and the residue was washed with THF $(109 \mathrm{~mL})$. The solvent was removed and the resulting oily residue was purified by crystallization from isopropanol $(440 \mathrm{~mL})$ to afford the title compound as a pale yellow solid $(6.510 \mathrm{~g}, 61 \%)$. Mp $113{ }^{\circ} \mathrm{C} .[\alpha]_{\mathrm{D}}{ }^{25}+9.8\left(c 1.0, \mathrm{CHCl}_{3}\right)$. IR $(\mathrm{KBr})$ : 3498, 3382, 3213, 3082, 2970, 1728, $1715 \mathrm{~cm}^{-1} .{ }^{1} \mathrm{H}$ NMR $\left(\mathrm{CDCl}_{3}, 400 \mathrm{MHz}\right): \delta 8.28(\mathrm{dd}, J=20.6,8.9$ $\mathrm{Hz}, 4 \mathrm{H}), 7.80(\mathrm{~s}, 1 \mathrm{H}), 5.58-5.40(\mathrm{~m}, 2 \mathrm{H}), 5.35-5.30(\mathrm{~m}, 1 \mathrm{H}), 4.91(\mathrm{bs}, 1 \mathrm{H}), 4.85$ (dd, J = 11.4, 9.3 Hz, 1H), 4.62 (dd, $J=11.4,6.3 \mathrm{~Hz}, 1 \mathrm{H}), 3.28-3.24(\mathrm{~m}, 1 \mathrm{H}), 2.85(\mathrm{ddd}, J=14.3,10.6,5.2 \mathrm{~Hz}, 1 \mathrm{H}), 2.42$ (dd, $J=14.3,8.1 \mathrm{~Hz}, 1 \mathrm{H}), 2.08(\mathrm{~s}, 3 \mathrm{H}) .{ }^{13} \mathrm{C} \mathrm{NMR}\left(\mathrm{CDCl}_{3}, 101 \mathrm{MHz}\right): \delta 170.3,165.0,158.9,153.1,151.8$, $150.8,146.2,141.9,135.2,130.9,125.9,123.8,113.6,74.6,65.9,57.4,48.7,35.5,21.3$. HRMS (ESI): $m / z$ calcd. for $\mathrm{C}_{21} \mathrm{H}_{20} \mathrm{ClN}_{6} \mathrm{O}_{6}^{+}[\mathrm{M}+\mathrm{H}]^{+}$487.1127; found 487.1132.

$((1 R, 3 S, 5 S)-5-A c e t o x y-3-(2-a m i n o-6-0 x 0-1 H$-purin-9(6H)-yl)-2-methylenecyclopentyl)methyl 4nitrobenzoate (14). A solution of $13(6.300 \mathrm{~g}, 12.94 \mathrm{mmol})$ in formic acid $80 \%(126 \mathrm{~mL})$ at $50{ }^{\circ} \mathrm{C}$ under $\mathrm{N}_{2}$ was stirred for $9 \mathrm{~h}$. The solvent was removed, $\mathrm{H}_{2} \mathrm{O}(72 \mathrm{~mL})$ was added and the suspension was stirred for $18 \mathrm{~h}$ at $\mathrm{rt}$. The suspension was filtered and the solid was dried to afford the title compound (14) as a yellow solid (5.590 g, 92\%). Mp $282{ }^{\circ} \mathrm{C} .[\alpha]_{\mathrm{D}}{ }^{25}+2.9(c$ 1.0, DMSO). IR (KBr): 3408, 3315, 3210, 3110, 2934, 2868, 1728, $1706 \mathrm{~cm}^{-1} .{ }^{1} \mathrm{H}$ NMR (DMSO- $\left.d_{6}, 400 \mathrm{MHz}\right) \delta: 11.08$ (bs, $\left.1 \mathrm{H}\right), 8.37$ (d, $J$ $=8.8 \mathrm{~Hz}, 2 \mathrm{H}), 8.24(\mathrm{~d}, J=8.8 \mathrm{~Hz}, 2 \mathrm{H}), 7.74(\mathrm{~s}, 1 \mathrm{H}), 6.66(\mathrm{bs}, 2 \mathrm{H}), 5.42-5.35(\mathrm{~m}, 1 \mathrm{H}), 5.35-5.31(\mathrm{~m}$, 1H), 5.27 (bs, 1H), $4.67(\mathrm{bs}, 1 \mathrm{H}), 4.59-4.55(\mathrm{~m}, 2 \mathrm{H}), 3.17-3.10(\mathrm{~m}, 1 \mathrm{H}), 2.70$ (ddd, $J=13.6,11.3,5.3$ $\mathrm{Hz}, 1 \mathrm{H}), 2.34-2.25$ (m, 1H), 2.01 (s, 3H). ${ }^{13} \mathrm{C}$ NMR (DMSO- $\left.d_{6}, 101 \mathrm{MHz}\right) \delta: 169.9,164.3,156.8,153.5$, 151.2, 150.3, 147.8, 136.1, 135.1, 130.7, 123.9, 116.5, 111.2, 74.1, 65.6, 55.2, 47.8, 35.2, 21.0. HRMS (ESI): $m / z$ calcd. for $\mathrm{C}_{21} \mathrm{H}_{21} \mathrm{~N}_{6} \mathrm{O}_{7}^{+}[\mathrm{M}+\mathrm{H}]^{+}$469.1466; found 469.1461 .

\section{2-Amino-9-((1S,3R,4S)-4-hydroxy-3-(hydroxymethyl)-2-methylenecyclopentyl)-1H-purin-6(9H)-}

one monohydrate (1). A solution of $\mathrm{MeONa}(30 \%, 4.10 \mathrm{~mL}, 22.20 \mathrm{mmol})$ was added dropwise to a solution of $14(5.200 \mathrm{~g}, 11.10 \mathrm{mmol})$ in anhydrous $\mathrm{MeOH}(40 \mathrm{~mL})$ at $\mathrm{rt}$ under $\mathrm{N}_{2}$. The mixture was 
stirred for $30 \mathrm{~min}$ at $\mathrm{rt}$ and cooled to $0{ }^{\circ} \mathrm{C}$. MTBE $(52 \mathrm{~mL})$ was added and the mixture was neutralized $(\mathrm{pH}=7)$ with $\mathrm{HCl}$. The phases were separated and the aqueous layer was extracted with MTBE $(50 \mathrm{~mL})$. The volume of the aqueous phase was reduced to $45 \mathrm{~mL}$ by distillation. The suspension was heated at $85^{\circ} \mathrm{C}$ and was slowly cooled to $\mathrm{rt}$ and stirred for $15 \mathrm{~h}$. After filtration the isolated solid was dried under vacuum to afford the title compound (1) as a white solid with a $6.5 \%$ water content (as determined by Karl Fischer titration) and $98.8 \%$ HPLC purity $\left(2.370 \mathrm{~g}, 72 \%\right.$ yield). This white solid $\mathbf{1}^{5 \mathrm{a}}$ was recrystallized from water to afford 1 (2.102 g, 64\% overall yield, 99.47\% HPLC purity) with a $6.7 \%$ water content (as determined by Karl Fischer titration). Mp $248{ }^{\circ} \mathrm{C} .[\alpha]_{\mathrm{D}}{ }^{25}+35.0\left(c 0.4, \mathrm{H}_{2} \mathrm{O}\right)$. IR (ATR): $3445,3361,3296,3175,3113,2951,2858,2626,1709 \mathrm{~cm}^{-1} .{ }^{1} \mathrm{H}$ NMR (DMSO- $\left.d_{6}, 400 \mathrm{MHz}\right) \delta: 10.59$ (s, 1H), $7.66(\mathrm{~s}, 1 \mathrm{H}), 6.42(\mathrm{bs}, 2 \mathrm{H}), 5.36(\mathrm{ddt}, J=10.6,7.8,2.7 \mathrm{~Hz}, 1 \mathrm{H}), 5.10(\mathrm{dd}, J=2.7,2.2 \mathrm{~Hz}, 1 \mathrm{H})$, $4.87(\mathrm{~d}, J=3.1 \mathrm{~Hz}, 1 \mathrm{H}), 4.84(\mathrm{t}, J=5.3 \mathrm{~Hz}, 1 \mathrm{H}), 4.56(\mathrm{t}, J=2.4 \mathrm{~Hz}, 1 \mathrm{H}), 4.23(\mathrm{~m}, 1 \mathrm{H}), 3.53(\mathrm{~m}, 2 \mathrm{H})$, $2.52(\mathrm{~m}, 1 \mathrm{H}), 2.22(\mathrm{ddd}, J=12.6,10.8,4.6 \mathrm{~Hz}, 1 \mathrm{H}), 2.04(\mathrm{ddt}, J=12.6,7.7,1.9 \mathrm{~Hz}, 1 \mathrm{H}) .{ }^{13} \mathrm{C} \mathrm{NMR}$ (DMSO-d $\left.d_{6}, 101 \mathrm{MHz}\right) \delta: 156.9,153.5,151.5,151.3,136.0,116.2,109.3,70.4,63.1,55.2,54.1,39.2$. HRMS (ESI): $m / z$ calcd. for $\mathrm{C}_{12} \mathrm{H}_{16} \mathrm{~N}_{5} \mathrm{O}_{3}{ }^{+}[\mathrm{M}+\mathrm{H}]^{+} 278.1253$; found 278.1262.

ACKNOWLEDGMENT. This work was supported by the Spanish Ministerio de Educación y Ciencia (Grants PET2008-0209 and IPT-2011-1005-900000).

\section{SUPPORTING INFORMATION}

${ }^{1} \mathrm{H}$ and ${ }^{13} \mathrm{C}$ NMR spectra of 1, 3a-e, 4b-k, 5b, 5g-h, 5k-m, 6, 7a-f, 13 and 14. This material is available free of charge via the Internet at http://pubs.acs.org.

\section{REFERENCES AND FOOTNOTES}


1. Hepatitis B; Fact sheet No. 204; World Health Organization, July 2012. http://www.who.int/mediacentre/factsheets/fs204/en/index.html (accessed March 22, 2013).

2. Dienstag, J. L. N. Engl. J. Med. 2008, 359, 1486-1500.

3. Scott, L. J.; Keating, G. M. Drugs 2009, 69, 1003-1033.

4. (a) Zahler, R.; Slusarchyk, W. A. Eur. Pat. EP0481754 B1, August 20, 1997. (b) Bisacchi, G. S.; Sundeen, J. E. WO9809964 A1, August 26, 1997.

5. (a) Bisacchi, G. S.; Chao, S. T.; Bachard, C.; Daris, J. P.; Innaimo, S.; Jacobs, G. A.; Kocy, O.; Lapointe, P.; Martel, A.; Merchant, Z.; Slusarchyk, W. A.; Sundeen, J. E.; Young, M. G.; Colonno, R.; Zahler, R. Bioorg. Med. Chem. Lett. 1997, 7, 127-132. (b) Innaimo, S. F.; Seifer, M.; Bisacchi, G. S.; Standring, D. N.; Zahler, R.; Colonno, R. J. Antimicrob. Agents Chemother. 1997, $41,1444-1448$.

6. (a) Gu, Y.; Cai, R.; Sun, X.; Zhu, H.; Zhao, Y. (Suzhou Well-Bridge Biological Technology Co., Ltd., Peop. Rep. China) CN102924454, A, February 13, 2013. (b) Jung, I. H.; Jang, M. S.; Kim, G. N. (Sungwun Pharmacopia Co., Ltd., S. Korea; Hanseo Chemical Co., Ltd.) KR2012091971, A, August 20, 2012. (c) Chen, H.; Jin, Y. (Shanghai Yonghong Industry Group Chemical Technology Co., Ltd., Peop. Rep. China) CN102477036, A, May 30, 2012. (d) Zheng, Z. (Ausun Pharmatech Co. Ltd., Peop. Rep. China) WO2012006964, A1, January 19, 2012. (e) Alberico, D.; Gorin, B.; Beharrilall, R.; Dixon, C.; Clayton, J.; Rexon, V. WO2011150513, A1, December 8, 2011. (f) Xu, K.; Wang, J.; Zhong, D.; Li, Z.; Hao, J. (Hainan Weikang Pharmaceutical (Qianshan) Co., Ltd., Peop. Rep. China) CN102225938, A, October 26, 2011. (g) Hu, T.-C.; Huang, H.-T. (Scinopharm Taiwan Ltd.) US2011201809, A1, August 18, 2011. (h) Li, G.; Qiu, B.; Yang, X.; Chen, S. (Fujian Cosunter Pharmaceutical Co., Ltd., Peop. Rep. China) CN102491960, A, Jun 13, 2012. (i) Lee, J. H.; Park, G. S.; Kim, J. H.; Choi, T. J.; Lee, J. E.; Han, 
J. H.; Bang, H. J.; Jung, S. Y.; Chang, Y. K.; Lee, G. S., Kim, M. S. (Hanmi Holdings Co., Ltd., S. Korea) WO2011046303, A2, April 21 2011. (j) Lee, J.; Park, G.-S.; Kim, J. H.; Lee, J. E.; Park, C. H.; Choi, T. J.; Park, E-J.; Kim, C. K.; Lim, E. J.; Chang, Y.-K.; Lee, G. S. (Hanmi Pharm. Ind. Co., Ltd., S. Korea) WO2010074534, A2, July 1, 2010. (k) Fang, Y.; Li, C.; Yin, F. (Hande Pharma Ltd., Peop. Rep. China) CN101891741, A, November 24, 2010. (1) Lei, X.; Lin, G.; Zeng, Y. (Fudan University, Peop. Rep. China) CN101781301, A, July 21, 2010. (m) Zhou, Z.; Wei, X.; Xu, X.; Chen, H. (Shanghai Pharmaceutical Co., Ltd., Peop. Rep. China) CN101759698, A, June 30, 2010. (n) Zeng, Y.; Wang, Z.; Gao, D.; Xu, Z. (Anhui Biochem. United Pharmaceutical Co., Ltd., Peop. Rep. China) CN101531660, A, September 16, 2009. (o) Liu, K.; Li, Y.; Wang, H.; Gao, X.; Tao, X.; Zhao, P.; Luo, G.; Tan, Y.; Yin, H.; Zhang, J. (Leadingpharm Laboratories Inc., Peop. Rep. China) CN 101337962, A, January 07, 2009. (p) Zhao, J.; Li, X.; Zhu, J.; Lou, J.; Zhou, X.; Cai, X.; Dong, Y.; Ye, X.; Zhang, M.; Xu, Z.; Wei, W.; Liu, W. (Hangzhou Shengyou Pharmaceutical Technology Co., Ltd., Peop. Rep. China; Tianjin Taipu Medicine Science and Technology Development Co., Ltd.; Shanghai Guochuang Pharmaceutical Co., Ltd.) CN101210015, A, July 02, 2008. (q) Kang, H. Fujian Guangshengtang Pharmaceutical Co., Ltd., Peop. Rep. China) CN101182322, A, May 21, 2008. (r) Yan, H. CN101148450, A, March 26, 2008. (s) Yuan, J.; Zhang, X.; Liu, F.; Zhang, K.; Ye, X.; Ge, Y. (Jiangsu Chia-Tai Tianqing Pharmaceutical Co., Ltd., Peop. Rep. China; Brightgene Bio-Medical Tech Ltd.) CN101130542, A, February 27, 2008. (t) Jiang, W.; Wang, W.; Hu, Y. (SFFT Developing Co., Ltd., Peop. Rep. China) CN101050216, A, October 10, 2007. (u) Chen, Y.; Han, S.; Yin, J.; Sun, T.; Cai, W.; Zhang, Y.; Ruan, G.; Zhu, Q.; Wang, X. (Shanghai Yangfan Pharmaceutical Technology Co., Ltd., Peop. Rep. China; Jiangsu Yangtze River Pharmaceutical Group) CN101012228, A, August 08, 2007. (v) Zhang, L.; Zeng, Z.; Yang, L.; Guo, L. (Shanghai Zhongxia Chemical Co., Ltd., Peop. Rep. China) CN1861602, A, November 15, 2006. (w) Zhou, M. X.; Reiff, E. A.; Vemishetti, P.; Pendri, Y. R.; Singh, A. K.; Prasad, S. J.; Dhokte, U. P.; Qian, X.; Mountford, P.; Hartung, K. 
B.; Sailes, H. (Bristol-Myers Squibb Company, USA), WO2005118585, A1, December 15, 2005.

(x) Pendri, Y. R.; Chen, C. H.; Patel, S. S.; Evans, J. M.; Liang, J.; Kronenthal, D. R.; Powers, G.

L.; Prasad, S. J.; Bien, J. T.; Shi, Z.; Patel, R. N.; Chan, Y. Y.; Rijhwani, S. K.; Singh, A. K.; Wang, S.; Stojanovic, M.; Polniaszek, R.; Lewis, C.; Thottathil, J.; Krishnamurty, D.; Zhou, M. X.; Vemishetti, P. (Bristol-Myers Squibb Company, USA), WO2004052310, A3, December 10, 2003.

7. Guo, L. W.; Xiao, Y. J.; Yang, L. P. Chin. Chem. Lett. 2006, 17, 907-910.

8. (a) Ying, L.; Wang, Z. (Shanghai Changsen Pharmaceutical Co., Ltd., Peop. Rep. China) CN102863444, A, January 9, 2013. (b) Fan, M.; Mao, J.; Si, B.; Feng, J. (Shanghai Changsen Pharmaceutical Co., Ltd., Peop. Rep. China) CN102417506, A, April 18, 2012. (c) Liu, X.; Jiao, X.; Wu, Q.; Tian, C.; Li, R.; Xie, P. Tetrahedron Lett. 2012, 53, 3805-3807. (d) Zhou, B.; Li, Y. Tetrahedron Lett. 2012, 53, 502-504. (e) Rawal, R. K.; Singh, U. S.; Gadthula, S.; Chu, C. K. Curr. Protoc. Nucleic Acid Chem. 2011, 47, 14.7.1-14.7.17.

9. This work has been partially reported in the following patents: (a) Bartra, M.; Berenguer, R.; Velasco, J.; Ariza, J.; Farràs, J.; García, J. (Esteve Química, S.A., Spain) WO2012085209, A1, June 28, 2012. (b) Berenguer, R.; Badia, L.; Gasanz, Y.; Velasco, J.; Ariza, X. (Esteve Química, S.A., Spain) PCT/EP2012/073438, November 24, 2011.

10. For recent reviews on the synthesis of carbocyclic nucleosides, see: (a) Boutureira, O.; Matheu, M. I.; Díaz, Y.; Castillón, S. Chem. Soc. Rev. 2013, [Advance Article], DOI: 10.1039/C3CS00003F. Published Online: March 7, 2013 http://pubs.rsc.org/en/content/articlelanding/2013/cs/c3cs00003f (accessed March 22, 2013). (b) Matyugina, E. S.; Khandazhinskaya, A. L.; Kochetkov, S. N. Russ. Chem. Rev. 2012, 81, 729-746. (c) Wang, J.; Rawal, R. K.; Chu, C. K. Recent Advances in Carbocyclic Nucleosides: Synthesis and Biological Activity. In Medicinal Chemistry of Nucleic 
Acids; Zhang, L.-H., Xi, Z., Chattopadhyaya, J., Eds.; Wiley \& Sons: Hoboken, 2011; pp 1-100.

11. (a) Nugent, W. A.; RajanBabu, T. V. J. Am. Chem. Soc. 1988, 110, 8561-8562. (b) RajanBabu, T. V.; Nugent, W. A. J. Am. Chem. Soc. 1994, 116, 986-997. For reviews, see: (c) Rossi, B.; Prosperini, S.; Pastori, N.; Clerici, A.; Punta, C. Molecules, 2012, 17, 14700-14732. (d) Cuerva, J. M.; Justicia, J.; Oller-López, J. L.; Bazdi, B.; Oltra J. E. Mini-Rev. Org. Chem. 2006, 3, 23-35. (e) Cuerva, J. M.; Justicia, J.; Oller-López, J. L.; Oltra J. E. Top. Curr. Chem. 2006, 264, 63-91. (f) Barrero, A. F.; Quílez del Moral, J. F.; Sánchez, E. M.; Arteaga, J. F. Eur. J. Org. Chem. 2006, $1627-1641$.

12. Ziegler, F. E.; Sarpong, M. A. Tetrahedron 2003, 59, 9013-9018.

13. For a recent review, see: Ariza, X.; Garcia, J.; Romea, P.; Urpí, F. Synthesis 2011, 2175-2191.

14. Paterson, I.; Goodman, J. M.; Lister, M. A.; Schumann, R. C.; McClure, C. K.; Norcross, R. D. Tetrahedron 1990, 46, 4663-4684.

15. Paterson, I.; Perkins, M. V. Tetrahedron 1996, 52, 1811-1834 and references therein.

16. (a) Gansäuer, A.; Pierobon, M.; Bluhm, H. Angew. Chem. Int. Ed. 1998, 37, 101-103. (b) Andreas Gansäuer, A.; Bluhm, H.; Pierobon, M. J. Am. Chem. Soc. 1998, 120, 12849-12859.

17. Barrero, A. F.; Rosales, A.; Cuerva, J. M.; Oltra, J. E. Org. Lett. 2003, 5, 1935-1938.

18. Gansäuer, A.; Otte, M.; Shi, L. J. Am. Chem. Soc. 2011, 133, 416-417.

\section{SYNOPSIS TOC.}




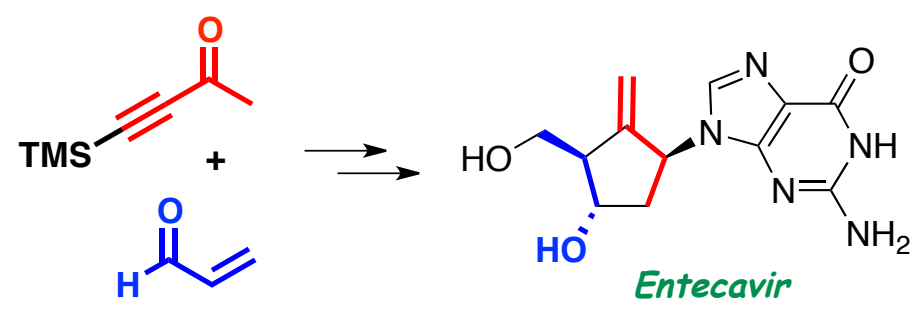

